\title{
MONETARY POLICY IN POST CRISIS INDONESIA: SOME LESSONS LEARNED ${ }^{1}$
}

\author{
Reza Anglingkusumo*) \\ Department of Finance, Vrije Universiteit - Amsterdam, \\ \& Tinbergen Institute - Amsterdam, \\ The Netherlands ${ }^{2}$
}

\begin{abstract}
The base money-targeting framework has shown signs of success in containing the reemergence of inflationary pressures in post crisis Indonesia. We have attributed this initial success to the plausible existence of the monetarist type economic relationships that have lent support to the effectiveness of the framework. Moreover, a clear cut and overriding commitment to maintain monetary stability clearly enhanced the framework's performance. To further improve the effectiveness of monetary policy in the future, we suggest the use of a full-information strategy in formulating monetary policy such as the one employed by the European Central Bank (ECB).
\end{abstract}

* MUPBLSTF - Direktorat Sumber Daya Manusia

1 The earlier versions of this paper were presented at the Conference on Economic Recovery and Reform (the Thammasat University and Bank of Thailand, Bangkok-Thailand, October 28-29, 2002), and the research seminars at the Tinbergen Institute Amsterdam-Netherlands, and the Indonesia Project - Australian National University, Canberra-Australia. Author wishes to thank Fadhil Nugroho of the Monetary Statistics Department and Andi Reina Sari from the Real Sector Statistics Department, Bank Indonesia, Jakarta - Indonesia, for data support. Usual disclaimers apply and all errors are mine.

2 Author is a research officer at Bank Indonesia currently on leave for foreign study. Author 's correspondence address is Vrije Universiteit, FEWEB, Department of Finance, De Boelelaan 1105, 1081 HV, Amsterdam, The Netherlands, or ranglingkusum@feweb.vu.nl 


\section{INTRODUCTION}

Since early 1999, monetary policy in Indonesia has been conducted using the so-called base money-targeting framework jointly implemented by Bank Indonesia (BI) and the International Monetary Fund (IMF) ${ }^{3}$. The Memorandum of Economic and Financial Policies (MEFP) in March 161999 assigned monetary policy with an explicit base-money target and implicit net domestic assets (NDA) and net international reserves (NIR) targets. This was to replace the explicit NDA target with implicit base money and NIR targets that had been used previously during the height of the crisis stabilization period in $1998^{4}$. This explicit base money targeting framework was designed to operate under the freely floating exchange rate regime with a capital flows monitoring system. The conduct of policy was planned to be a rule-based policy defined in terms of the performance criteria and indicative targets for the level of base money, based upon cautious assessments on the development in money demand. The role and scope of monetary policy were set to ensure price stability and reduce the volatility in the rupiah to US dollar (Rp/USD) foreign exchange rate via a prudent monetary control. This set up has been the official framework of monetary policy in Indonesia since then ${ }^{5}$.

In a nutshell, the base money targeting framework is the assignment of explicit annual performance criteria and indicative targets for the level of nominal base money that are broken down into quarterly performance criteria and indicative targets. This directly implies the assignment of explicit performance criteria and indicative targets for the annual growth of nominal base money. Base money is defined as the sum of the total nominal coins and notes (cash) in circulation, the nominal commercial bank's deposits at BI in rupiah, the nominal private sectors' demand deposit at $\mathrm{BI}$, and the nominal aggregate reserves deficiency. The performance criteria are the values of base money that must be maintained by BI as the IMF team conducts quarterly progress reviews. The indicative targets, on the other hand, are the indications of the values of base money that will be maintained by BI for the period longer than the next progress review.

As it stood in the end of 2002, the base money-targeting framework had been quite successful in containing the inflationary pressures and stabilizing the Rp/USD exchange rate. Inflation in end of 2002 was contained slightly above the single digit target of $10 \%$ yoy and the exchange rate was stabilized at around Rp 8900 / USD despite the Bali fiasco. We

3 This is documented in the 1st supplement of the Memorandum of Economic and Financial Policies (MEFP) under the extended arrangement signed by the Government of Indonesia (GOI) and BI in March 16, 1999 and submitted to the managing director of the IMF.

4 Accordingly, this paper defines the post crisis era as the era since March 161999 onwards.

5 It must be noted that the base money targeting framework was originally proposed in the MEFP signed in October 31,1997 . However, as the currency crisis grew into the full-blown monetary and economic crisis in 1998, a shift to an NDA target was implemented (1st MEFP supplement signed in April 10, 1998). 
argue that much of these signs of a successful performance are related to (1) the plausible existence of the monetarist type economic relationships that have prevailed in Indonesia since 1980s and lent support to the effectiveness of the framework, and (2) the overriding commitment to promote price stability in post crisis Indonesia ${ }^{6}$. Accordingly this paper will discuss these two sources of satisfactory performance in promoting nominal stability in post crisis Indonesia and draw several lessons for improving the overall monetary policy framework in the future.

To organize the discussions, section II outlines some stylized facts on the plausible existence of the monetarist type economic relationships in Indonesia since 1980. Section III discusses the post crisis experience with base money targeting framework and draws some lessons. Section IV puts forward some suggestions for improving BI's monetary policy framework in the future. Section V concludes.

\section{STYLIZED FACTS ON THE MONETARIST TYPE ECONOMIC RELATIONSHIPS IN INDONESIA}

Empirical studies conducted to see the link between nominal money growth and inflation in Indonesia since 1980 suggest that after some variable lags, inflation could be a phenomenon of monetary disequilibria ${ }^{7}$. This is in particular supported by the possible presence of macroeconomic relationships such as presupposed by the classical quantity theory. Moreover, in the era of a freely floating exchange rate regime in Indonesia, monetary disequilibria ${ }^{8}$ could also play a potential role in affecting the stability of the nominal Rp/ USD exchange rate, especially when the supply of USD is limited and political uncertainties dominate the market.

Table 1 summarizes the empirical findings on the lead-lag relationships between the turning points of $\mathrm{CPI}$ inflation and the turning points of the annual growth of nominal money aggregates in Indonesia since $1980^{\circ}$. These turning points are derived using the BryBoschan algorithms ${ }^{10}$ and the verification tests on these turning points are conducted using the autoregressive markov regime switching regressions ${ }^{11}$. We have studied 9 definitions of

6 Price stability is defined as an economic environment where the actual and the expected inflation that prevail in the market are maintained at a low and stable level.

7 Due to limited space, most of the detailed calculations and results of the studies mentioned in this paper can be requested directly from the author.

8 Monetary disequilibria is defined as the excess growth of nominal money above the real need of the economy.

9 Annual growth of monetary aggregates and CPI are the year on year growth based on monthly data since January 1979.

10 Literatures on this particular subject can be found in Bry-Boschan (1971) and Niemiera-Klein (1994).

11 For the methodology to verify turning points using the markov regime switching regressions see Hamilton (1989, 1990), for the methodology to estimate the markov regime switching regressions see Hamilton (1989, 1990, 1994) and Franses - van Dijk (2000). Computerised EM algorithms for estimating the markov regime switching regressions is available from Krolzig (1998). 
money, namely (1) the nominal coins and notes (cash) in circulations, (2) the non-cash component of nominal base money, (3) the nominal base money, (4) the nominal demand deposits, (5) the nominal M1, (6) the nominal M2, (7) the nominal total quasi money, (8) the rupiah denominated nominal quasi money, and (9) the non-rupiah denominated nominal quasi money ${ }^{12}$. Nominal base money is the sum of (1) and (2); nominal M1 is the sum of (1) and (4); nominal M2 is composed of (5) and (7); and, nominal total quasi money is composed of (8) and (9). We discuss the results of the study below ${ }^{13}$.

Table 1. The Results of Lead-Lag Analyses Between The Annual Growth of Nominal Money Aggregates and CPI Inflation in Indonesia since 1980

\begin{tabular}{|c|c|c|c|c|c|c|c|c|c|c|}
\hline \multirow{2}{*}{\multicolumn{2}{|c|}{$\begin{array}{l}\text { TURNING POINIS } \\
\text { OF CPI INFLATION }\end{array}$}} & \multicolumn{9}{|c|}{$\begin{array}{l}\text { LEAD }(-) / \text { LAG }(+) \text { PROFILE (INMONTHS) } \\
\end{array}$} \\
\hline & & \multirow{2}{*}{\multicolumn{2}{|c|}{\begin{tabular}{c|c|} 
CASH & $\begin{array}{c}\text { NONCASH } \\
\text { BASE MONEY }\end{array}$ \\
8.0 & -12.0 \\
\end{tabular}}} & \multirow{2}{*}{\begin{tabular}{|c}
$\begin{array}{c}\text { BASE } \\
\text { MONEY }\end{array}$ \\
16.0
\end{tabular}} & \multirow{2}{*}{\begin{tabular}{|c|}
$\begin{array}{c}\text { DEMAND } \\
\text { DEPOSIT }\end{array}$ \\
-13.0
\end{tabular}} & \multirow{2}{*}{\begin{tabular}{|c|} 
M1 \\
Missed
\end{tabular}} & \multirow{2}{*}{$\begin{array}{l}\text { M2 } \\
-3.0\end{array}$} & \multirow{2}{*}{$\begin{array}{c}\text { TOTAL } \\
\text { QUASI } \\
4.0\end{array}$} & $\begin{array}{l}\text { QUASI } \\
\text { IN RP } \\
\end{array}$ & $\begin{array}{c}\text { QUASI } \\
\text { NON RP } \\
\end{array}$ \\
\hline Trough & November 1981 & & & & & & & & na. & n.a. \\
\hline Peak & August 1983 & -2.0 & 5.0 & 7.0 & -13.0 & Missed & 6.0 & 6.0 & na. & na. \\
\hline Trough & July 1986 & -13.0 & 8.0 & Missed & -32.0 & -32.0 & -20.0 & 7.0 & na. & na. \\
\hline Peak & August 1987 & -11.0 & 9.0 & Missed & Missed & -9.0 & Missed & 10.0 & na. & na. \\
\hline Trough & May 1990 & -24.0 & -8.0 & -12.0 & Missed & -24.0 & -32.0 & -9.0 & na. & n.a. \\
\hline Peak & October 1990 & -1.0 & 4.0 & -13.0 & Missed & Missed & -2.0 & 2.0 & 0.0 & 3.0 \\
\hline Trough & November 1992 & -14.0 & 6.0 & -11.0 & 1.0 & -16.0 & 7.0 & 7.0 & -10.0 & 14.0 \\
\hline Peak & May 1995 & -3.0 & 16.0 & -3.0 & Missed & -15.0 & 12.0 & 12.0 & 11.0 & 9.0 \\
\hline Trough & February 1997 & -12.0 & 9.0 & 9.0 & Missed & 7.0 & 9.0 & 10.0 & 10.0 & 2.0 \\
\hline Peak & September 1998 & -2.0 & 2.0 & 2.0 & -1.0 & -1.0 & -3.0 & -3.0 & 3.0 & -8.0 \\
\hline Trough & March 2000 & -8.0 & -4.0 & -8.0 & -9.0 & -9.0 & 6.0 & 6.0 & 4.0 & -9.0 \\
\hline Peak & February 2002 & -20.0 & n.a. & -15.0 & -14.0 & -19.0 & -10.0 & -10.0 & -2.0 & -10.0 \\
\hline & "Mean & -8.5 & 3.2 & -2.8 & 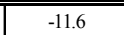 & \begin{tabular}{c|}
-13.1 \\
\end{tabular} & \begin{tabular}{c|}
-2.7 \\
\end{tabular} & 2.8 & 2.3 & 0.1 \\
\hline & Standard Deviation & 9.0 & 8.2 & 10.8 & 10.8 & 11.8 & 13.5 & 7.6 & 7.2 & 9.4 \\
\hline & Median & -9.5 & 5.0 & -5.5 & -13.0 & -15.0 & -2.0 & 6.0 & 3.0 & 2.0 \\
\hline & Skewness & 0.0 & -0.6 & 0.6 & -1.0 & 0.2 & -1.2 & -0.7 & -0.5 & 0.3 \\
\hline & Kurtosis & -0.2 & -0.1 & -1.1 & 1.8 & 0.0 & 0.9 & -1.0 & 0.2 & -1.6 \\
\hline & \% \%EAD & $92 \%$ & $25 \%$ & 50\% & $50 \%$ & $67 \%$ & $50 \%$ & $33 \%$ & $29 \%$ & $43 \%$ \\
\hline & $\%$ LAG & $8 \%$ & $67 \%$ & $33 \%$ & $8 \%$ & $8 \%$ & $42 \%$ & $67 \%$ & $57 \%$ & $57 \%$ \\
\hline & $\%$ COINCIDENT & $0 \%$ & $0 \%$ & $0 \%$ & $0 \%$ & $0 \%$ & $0 \%$ & $0 \%$ & $14 \%$ & $0 \%$ \\
\hline & $\%$ MISSED & $0 \%$ & $0 \%$ & $17 \%$ & $42 \%$ & $25 \%$ & $8 \%$ & $0 \%$ & $0 \%$ & $0 \%$ \\
\hline \multicolumn{11}{|c|}{ LEAD (-) / LAG (+) INQUARTERS } \\
\hline & Average & -2.8 & 1.1 & -0.9 & -3.9 & 4.4 & -0.9 & 0.9 & 0.8 & 0.0 \\
\hline & Standard Deviation & 3.0 & 2.7 & 3.6 & 3.6 & 3.9 & 4.5 & 2.5 & 2.4 & 3.1 \\
\hline & Median & -3.2 & 1.7 & -1.8 & -4.3 & -5.0 & -0.7 & 2.0 & 1.0 & 0.7 \\
\hline & $\begin{array}{c}\text { TYPE } \\
\text { LENGTH }\end{array}$ & \begin{tabular}{|c} 
LEADING \\
LONG
\end{tabular} & $\begin{array}{c}\text { LAGGING } \\
\text { SHORT }\end{array}$ & $\begin{array}{c}\text { LEADING } \\
\text { SHORT }\end{array}$ & $\begin{array}{c}\text { LEADING } \\
\text { LONG }\end{array}$ & $\begin{array}{c}\text { LEADING } \\
\text { LONG }\end{array}$ & COINCIDE & \begin{tabular}{|c|} 
LAGGING \\
SHORT
\end{tabular} & $\begin{array}{c}\text { LAGGING } \\
\text { SHORT }\end{array}$ & COINCIDE \\
\hline & ROBUSTNESS & $\begin{array}{l}\text { ROBUST } \\
\text { STRONG }\end{array}$ & $\begin{array}{l}\text { NOT ROBUST } \\
\text { STRONG }\end{array}$ & $\begin{array}{l}\text { NOT ROBUST } \\
\text { WEAK }\end{array}$ & $\begin{array}{c}\text { NOT ROBUST } \\
\text { WEAK }\end{array}$ & $\begin{array}{c}\text { NOT ROBUST } \\
\text { WEAK }\end{array}$ & $\begin{array}{c}\text { NOT ROBUST } \\
\text { WEAK }\end{array}$ & $\begin{array}{c}\text { NOT ROBUST } \\
\text { STRONG }\end{array}$ & $\begin{array}{c}\text { NOT ROBUST } \\
\text { WEAK }\end{array}$ & $\begin{array}{c}\text { NOT ROBUST } \\
\text { WEAK }\end{array}$ \\
\hline
\end{tabular}

It can be studied from table 1 that there are 12 episodes of turning points in the CPI inflation series. The only series whose turning points have persistently led the turning points of CPI inflation series is the annual growth of nominal cash (coins and notes) in

12 Quasi money is the time deposits at commercial banks. The data for the break down between the rupiah and non rupiah quasi money are only available from January 1990 onwards. Accordingly in table 1 we cannot report the relationships between the two and CPI inflation before 1990.

13 Detail results on the Bry-Boschan turning points and the verification using markov regime switching regressions can be requested directly from the author. 
circulation ${ }^{14}$. Historically, the turning points of the annual growth of nominal cash lead the turning points of CPI inflation $92 \%$ of the time with only one occasion where former lagged the later in early 1980. In months, the turning points of the former lead the turning points of the later on average by 8,5 months with a standard deviation of $+/-9$ months. Accordingly, the changes in the annual growth of nominal cash could coincide with the changes in CPI inflation within a quarter or the former could happen 17,5 months or 6 quarters in advance. Hence, we can characterize the annual growth of nominal cash as a long leading indicator of CPI inflation ${ }^{15}$. In addition, since it never missed the turning points of CPI inflation in all episodes, then the annual growth of nominal cash is also a strong leading indicator of CPI inflation ${ }^{16}$.

The long and strong lead relationship from the annual growth of nominal cash to CPI inflation as mentioned above is also robust across regimes. This is because such a lead relationship has survived several episodes of major structural and policy regime changes in Indonesia, namely (1) the interest rate liberalization initiated in June $1983^{17}$, (2) the banking sector deregulation initiated in October 1988, (3) the capital market deregulation in 1989 and early 1990s, (4) the period of strong economic growth and capital flows in 1990s, (5) the currency and monetary crisis since late 1997 until end of 1998, and (6) the shift from the managed floating exchange rate regime to the freely floating regime in August $1997^{18}$. Entering the post crisis period the relationship stayed. Therefore, the leading relationship from the annual growth of nominal cash to CPI inflation could be expected to persist.

With regards to the relationships of the other monetary aggregates with CPI inflation, we can conclude, from table 1 , the following 6 additional relationships that have prevailed in Indonesia since 1980:

(1) By excluding the episodes in 1980s, the annual growth of nominal base money is a short but strong leading indicator of CPI Inflation,

14 The negative figures in the table indicate the lead-time in months, while positive figures indicate the lag- time in months. These apply also for the other results in table 1.

15 As the cut off criteria, we have arbitrarily defined a long leading indicator of inflation as an indicator that leads CPI inflation by at least 3 quarters on average; while, a short leading indicator of inflation is defined as an indicator that leads CPI inflation by at most 2 quarters on average. Similar cut-off criteria apply for the lagging indicators.

16 For later discussions, a strong indicator is defined as an indicator whose turning points missed the turning points of CPI inflation less than $30 \%$ of the time, or consistently has had a lead or lag relationship with CPI inflation at least $60 \%$ of the time.

17 An interesting point to note is that prior to the interest rate liberalization in June 1983, there was one episode where the turning point of the annual growth of nominal cash lagged the turning point of CPI inflation. Afterwards, the turning points of the former consistently led those of the later. Therefore, it must be highlighted that the robustness of the annual growth of nominal cash in leading the CPI inflation series holds only since the post interest rate liberalization era.

18 Accordingly from here on, a robust indicator is defined as an indicator that has had a consistent lead or lag relationship with CPI inflation across the above seven regime changes. 
(2) The annual growth of the nominal non-cash component of base money is a short but strong lagging indicator of CPI inflation,

(3) The annual growth of nominal M1 is a long leading indicator of CPI inflation,

(4) The annual growth of nominal non-rupiah quasi money could be expected to have a strong leading indicator property on CPI inflation in the post crisis era,

(5) The annual growths of nominal M2, total quasi money, and rupiah quasi money have no leading indicator properties on CPI inflation. They are at most coinciding with CPI inflation over time,

(6) Given point (4) it could be expected that the annual growth of nominal M2 will start to have a short lead on CPI inflation in post crisis era.

The above conclusions reassert the conclusion that none of the other monetary aggregates matches the superiority of the lead relationship from the annual growth of nominal cash to CPI inflation. Given the uniqueness of the annual growth of nominal cash series, we scrutinize its relationship with CPI inflation further.

\section{Graph 1a. The Annual Growth of Nominal Cash, Real Demand for Cash Balance, and CPI [Pre-Crisis Period]}

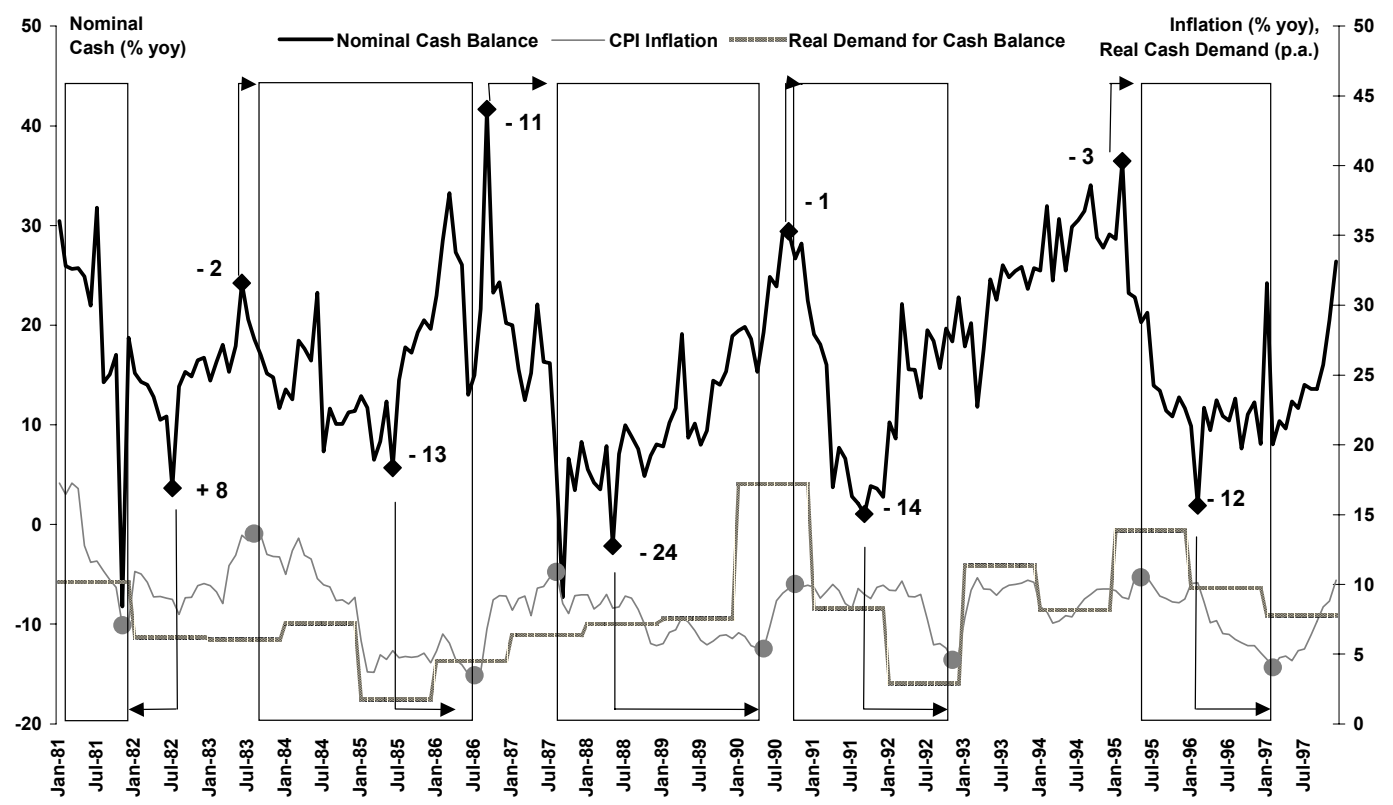




\section{Graph 1b. The Annual Growth of Nominal Cash, Real Demand} for Cash Balance, and CPI [Crisis and Post Crisis Period]

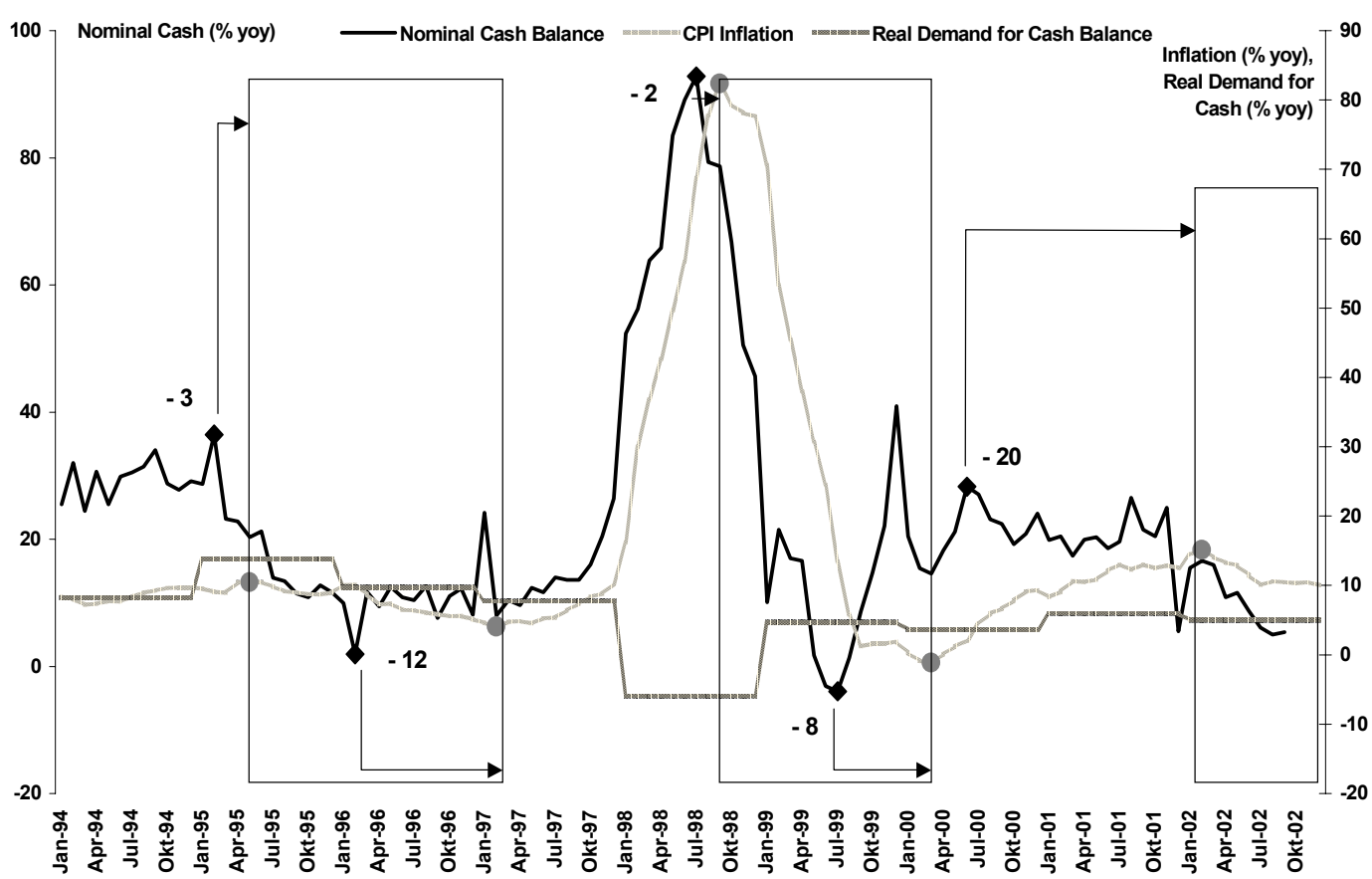

Graph 1a and $1 \mathrm{~b}$ plot the two series since 1980. In the two graphs, the circle dots mark the turning points of CPI inflation series, while the diamond dots mark the turning points of the annual growth of nominal cash series. The boxes in the graphs mark the periods from peaks to troughs in CPI inflation series (or the phases of inflation downturns). The arrows pointing right signify the lead relationships from the turning points of the annual growth of nominal cash to the turning points of CPI inflation. Conversely, the arrow pointing left signifies the lag relationship. We also plot the average annual growth of the real domestic households' consumption spending ${ }^{19}$. This series measures the real demand for cash balance that have prevailed in the economy and will be used later to illustrate the extent of monetary disequilibria in terms of cash in circulation above / below the real consumption need of the economy.

As depicted in the graphs, the lead relationship from the turning points of the annual growth of nominal cash to the turning points of CPI inflation varies overtime. Some are short and some are quite long. In all episodes the trend increase or decrease in the annual growth

19 Since in our analysis we use monthly series, then the yearly observations of this series are used to fill the monthly observations in a given year. 
Table 2. The Chronology of Turning Points and Relationship Between the Annual Growth of Nominal Cash and CPI Inflation since 1980

\begin{tabular}{|c|c|c|c|c|c|}
\hline \multicolumn{2}{|c|}{ Nominal Cash (Coins \& Notes) } & \multicolumn{2}{|l|}{ CPI Inflation } & \multicolumn{2}{|c|}{ Lead (-) / Lag (+) } \\
\hline PEAK & TROUGH & PEAK & TROUGH & PEAK & TROUGH \\
\hline $\begin{array}{l}\text { June } 1983 \\
\text { September } 1986 \\
\text { September } 1990 \\
\text { February } 1995 \\
\text { July } 1998 \\
\text { June } 2000\end{array}$ & $\begin{array}{l}\text { July } 1982 \\
\text { June } 1985 \\
\text { May } 1988 \\
\text { Septem ber } 1991 \\
\text { February } 1996 \\
\text { July } 1999\end{array}$ & $\begin{array}{l}\text { August } 1983 \\
\text { August } 1987 \\
\text { O ctober } 1990 \\
\text { May } 1995 \\
\text { Septem ber } 1998 \\
\text { February } 2002\end{array}$ & $\begin{array}{l}\text { November } 1981 \\
\text { July } 1986 \\
\text { May } 1990 \\
\text { Novem ber } 1992 \\
\text { February } 1997 \\
\text { March } 2000\end{array}$ & $\begin{array}{l}-2 \\
-11 \\
-1 \\
-3 \\
-2 \\
-20\end{array}$ & $\begin{array}{c}8 \\
-13 \\
-24 \\
-14 \\
-12 \\
-8\end{array}$ \\
\hline & LEAD AT PEAKS & LEAD AT TROUGHS & OVERALL & LEAD IN & UARTERS \\
\hline $\begin{array}{l}\text { Mean } \\
\text { Stand. Deviation } \\
\text { Maximum } \\
\text { Minimum } \\
\text { Mode } \\
\text { Median } \\
\text { Skewness } \\
\text { Kurtosis }\end{array}$ & $\begin{array}{l}-6.5 \\
7.6 \\
-20.0 \\
-1.0 \\
-2.0 \\
-2.5 \\
-1.5 \\
1.4\end{array}$ & $\begin{array}{c}-10.5 \\
10.5 \\
-24.0 \\
8.0 \\
\mathrm{n} . \mathrm{a} . \\
-12.5 \\
1.0 \\
2.4\end{array}$ & $\begin{array}{c}-8.5 \\
9.0 \\
-24.0 \\
8.0 \\
-2.0 \\
-9.5 \\
0.0 \\
-0.2\end{array}$ & $\begin{array}{l}\text { MEAN } \\
\text { STD. DEV } \\
\text { MEDIAN }\end{array}$ & $\begin{array}{l}-2.8 \\
3.0 \\
-3.2\end{array}$ \\
\hline
\end{tabular}

of nominal cash paves the way to the corresponding trend increase or decrease in CPI inflation. Table 2 gives more detail accounts on the relationship. In this table the chronologies of the turning points of the two series are presented. We also report the leading relationship at peaks and at troughs. The maximum lead is 24 months from the trough of the annual growth of nominal cash in May 1988 to the trough of CPI inflation in May 1990. The shortest lead is 1 month from the peak of the annual growth of nominal cash in September 1990 to the peak of CPI inflation in October 1990. The lead relationship is on average longer at troughs than at peaks. The average lead at troughs is 10,5 months with $\mathrm{a}+/-10,5$ months standard deviation. Thus the downturn phases of the annual growth of nominal cash could coincide with the downturn phases of CPI inflation within a quarter or the former could lead the later by 21 months or approximately 2 years. On the other hand, the average lead at peaks is only 6,5 months with $a+/-7,6$ months standard deviation. Hence, an upward phase in the annual growth of nominal cash could immediately be followed by an upward phase in CPI inflation or the first could happen 14,1 months earlier.

The presence of the lead relationship from the annual growth of nominal narrow money (base money, cash, and M1) to CPI inflation in Indonesia echoes the pronouncements of the monetarist school of thought such as put forward in Friedman and Schwartz (1963, 1982) and Friedman (1974)

First of all, the proponents of the monetarist school of thought have argued that (1) inflation is always and everywhere a monetary phenomenon, and (2) the effects of an excessive 
nominal money growth on inflation come to pass only after some long and variable lags. These assertions are rooted on the presupposition that the behaviours of nominal variables are always determined by the behaviours of other nominal variables. Since all the narrow money growth indicators that we have measured are nominal variables, then they are plausible explanatory variables for inflation, which certainly is a nominal variable. Using the classical quantity theory in the line of Irving Fisher, one can deduce that an excessive growth of nominal money is merely a veil. It affects only the price level and neutral towards the real activity (the classical dichotomy). Similarly, we argue that inflation in Indonesia could be a phenomenon of the excess growth of nominal narrow money, in particular the excess growth of nominal cash in circulation, above its real consumption need.

To prove the above argument one needs to confirm that (1) the growth rate of real consumption is a (weakly) exogenous factor that is not determined by the monetary disequilibria, and (2) inflation is an endogenous variable determined by the monetary disequilibria and not vice versa. We save the formal statistical tests in the appendix of this paper. It suffices to say at this stage that inflation could be a monetary phenomenon in Indonesia since 1980. This is deduced from the following statistical tests' results: (1) there exists a stable demand function for real narrow money balance (M1) that serves as the benchmark to measure the monetary disequilibria in terms of M1, (2) inflation is not a weakly exogenous variable in the real M1 demand system, (3) the fluctuations of real activities, defined as the real growth of the domestic households' consumption spending, is a weakly exogenous factor and not determined by the M1 disequilibria, (4) price level is long run homogenous and determined by the increase in nominal M1 in a one-on-one fashion, and (5) M1 disequilibria is a weakly exogenous variable that determines the acceleration of inflation.

However, before the above results can be upgraded into more certain results, a more rigorous common trend analysis must be done with regards to the cointegrating relationships in the long run real M1 demand system already obtained so far in the appendi $x^{20}$. Specifically, the use of the conventional Johansen-Juselius cointegration test is not appropriate when there may be a need to include an exogenous shift dummy in the cointegration analysis during the monetary crisis. If such a shift dummy is excluded, then a more rigorous statistical analysis to show the existence of a co-breaking vector among variables in the long run real M1 demand system is needed in line with the methodology developed in Hendry-Mizon (1998). Alternatively, one can also try to prove that the exclusion of a shift dummy to capture the possible monetary crisis break, does not matter statistically to the cointegrating relationships in the long run real M1 demand system. On this alternative approach, a

20 More certain results would lead to a conclusion that "inflation is indeed a monetary phenomenon in Indonesia since $1980 \mathrm{~s} "$ 
simulation to derive a new set of asymptotic critical values different from the OsterwaldLenum (1992) is needed in line with the latest methodology outlined in Johansen-MosconiNielsen (2000). However, by looking at the stability of the equilibrium real M1 demand function during the crisis as shown in the appendix, we suspect that the results of the tests will not be significantly altered once more rigorous tests and calculations are finalized on the co-breaking and critical values issues. We summarize these tests' results in the appendix.

Second, the channels into which the monetary disequilibria are transmitted into inflation could take on several forms. One of these is the well-known assertion that inflation is the effect of "too much money chasing too few goods". In this channel, suppliers are constrained by their capacity to produce and distribute goods. As a result, when too much money is available in the economy in nominal term, then the value of money in terms of the amount of real stock of goods that are available for purchase will decline. This decline in the value of money is reflected by the increase in the prices of goods supplied. Moreover, when the money in excess is growing continuously, then there would a continuous decline in the value of money in terms of the real growth of goods supplied in the economy. This continuous decline in the value of money is represented by price inflation in the goods market. But, why does not the real supply side adjust to the excess nominal money in circulation?

The answer rests on the characteristics of the long run supply side of the economy. It takes time to organise an increase in the total capacity to produce and distribute goods, and as a result the long run supply side is only slow to adjust. This adjustment can be even slower when there is a run away price inflation present in the goods market. This is because with nominal instability, it becomes harder for suppliers to conduct the long term planning on their real investment. Moreover, in the absence of nominal instability, as a real variable, the long run supply side of the economy is determined more by real factors rather than by nominal factors (the classical dichotomy). Conceptually, some plausible real factors that could affect the long run supply side are: (a) the degree of competitions in the goods and labour markets, (b) labour productivities and skills, (c) the existing level of technology, (d) the availability of natural resources and sufficient labour supplies, (e) new capital investments, (f) the comparative advantage of the domestic industries, and so on. Accordingly, the long run supply side will be mostly determined by government policies to: (a) improve the competitive climate of the economy, (b) support and promote technological progress, (c) improve the management of natural resources, (d) improve the skills of the labour force through educations, (e) improve the comparative advantage of the domestic industries, and (f) improve the quality of the private and public governance. Since these factors depend much on the policy choices of the government and not by the policy choices of the central bank, then the improvements in the long run supply side and real economic growth are determined mainly by the political will of the government. Hence, the long run supply side can be very rigid and the long run 
economic growth can be very sluggish if the political infra and superstructures of a country are not working properly.

Another transmission from the excess growth of nominal money to inflation is via the behaviour of the nominal exchange rate. This is in line with the propositions put forward by the proponents of the contemporary monetarist school of thought. Under this school of thought one can loosely put the works of Michael Mussa (1976), Rudiger Dornbusch (1976a, 1976b), and Jacob Frenkel (1976) among others, who have developed theories on the monetary aspects of exchange rate determination ${ }^{21}$. In a simple exposition the theory argues that in the presence of monetary equilibrium in foreign economy, domestic monetary disequilibria will be translated into the depreciations in the country's foreign exchange rate. Of course, this proposition assumes rationally behaving private agents in the financial market. Thus when agents see that domestically there is money in excess of the real need of the economy, amidst monetary equilibrium in foreign economy, then they expect the current domestic inflation to rise in the future relative to foreign inflation. This increase in private agents' inflation expectations will go directly into their declining expectations about the future fundamental support of the country's exchange rate (i.e. the purchasing power parity relation). As a result, private agents will favour foreign currency more than domestic currency today, causing the depreciations in the value of domestic currency relative to foreign currency.

Carrying the above money-exchange rate nexus forward, the declining value of domestic currency will then be transmitted into domestic prices via the import price pass-through effects. This constitutes a direct channel from the exchange rate to inflation. But there is also a less direct channel via the supply side of the economy. That is if the industrial output in the domestic supply side are loaded with import contents, then the depreciations in domestic currency will lower the capacity of the domestic supply side to produce. As a result, there will be a decline in the amount of goods supplied that causes inflation to emerge. The inflationary pressures will be amplified if amidst the supply downturn there is a continuous excess growth of nominal money in the economy. This continuous excess money will press the domestic exchange rate further down, causing a depreciation-inflation spiral. In addition, the effect of too much money chasing too few goods will put additional inflationary pressures in the goods market in due time, and lower the fundamental support of the exchange rate further, such that there will be an extra depreciation-inflation spiral. The combined effects will be a reduction in the real capacity to produce coupled by a run away inflation. The economy will move into a stagflation until the excess nominal money growth is stabilised at its real need.

The plausible presence of the money - exchange rate - inflation nexus in Indonesia is

21 Humprey (1977) provides a soft and easy review on the literatures. 
Graph 2. The Annual Growths of Nominal M1, Rp/USD,

Real Domestic Households' Consumption Spending, and CPI (Crisis and Post Crisis)

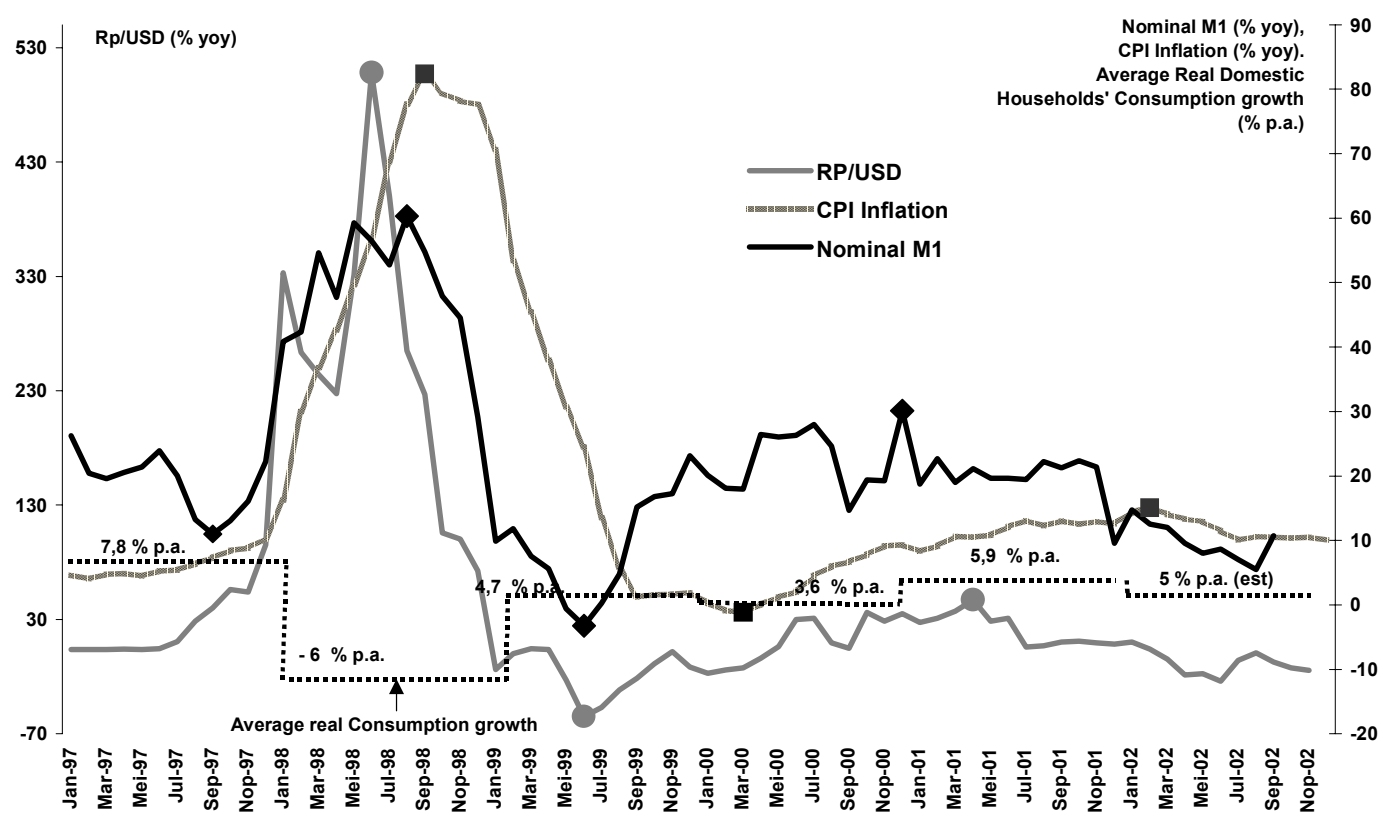

illustrated in graph 2. The graph depicts the time evolution of the growth rate of nominal M1, the annual changes of the Rp/USD exchange rate, and the CPI inflation since the floating of $\mathrm{Rp} / \mathrm{USD}$ in August 1997. We have deliberately chosen M1 as the representative monetary aggregate for it is the broadest definition of narrow money and represents both the nominal cash in circulation and the demand deposit ${ }^{22}$. It is also the money aggregate that we have shown as having a stable real money demand function [see appendix]. The peaks and troughs of each series are illustrated by the dots. The circle dots mark the turning points of the annual changes in Rp/USD exchange rate; the diamond dots mark the turning points of the annual growth of nominal M1; and, the square dots mark the turning points of CPI inflation. The broken lines represent the average annual growths of the real domestic households' consumption spending that have prevailed since 1997 to help illustrate the extent of the "monetary disequilibria" defined as the excess growth of nominal M1 above the average growth of the real households' consumption spending ${ }^{23}$. It is noticeable that throughout the period there has been strong "monetary disequilibria" present, except in mid-1999 and during year 2002.

22 We avoid using M2 for in it there is a strong component of quasi money denominated in foreign currency and it will cloud our analytical judgement.

23 Hence, for simplicity we have assumed that the expected real growth of the foreign economy carries less weight in affecting the domestic agents' economic decisions. 
Table 3. The Chronology of Turning Points of The Annual Growth of Nominal M1, Rp/USD, and CPI (Crisis and Post Crisis)

\begin{tabular}{|c|c|c|c|c|c|}
\hline \multicolumn{2}{|c|}{ Nominal M1 (y-0-y) } & \multicolumn{2}{|l|}{ Rp/USD (y-o-y) } & \multicolumn{2}{|c|}{ Months Lead (-)/ Lag (+) } \\
\hline PEAK & TROUGH & PEAK & TROUGH & PEAK & TROUGH \\
\hline $\begin{array}{l}\text { August } 1998 \\
\text { December } 2000\end{array}$ & June 1999 & $\begin{array}{l}\text { June } 1998 \\
\text { April } 2001\end{array}$ & June 1999 & $\begin{array}{c}2 \\
-4 \\
\end{array}$ & 0 \\
\hline & & & & In Months & In Quarters \\
\hline & & & \begin{tabular}{|l|} 
Mean \\
Stand. Deviation
\end{tabular} & $\begin{array}{c}-0.7 \\
3.1 \\
\end{array}$ & $\begin{array}{c}-0.2 \\
1.0 \\
\end{array}$ \\
\hline \multicolumn{2}{|l|}{ Rp/USD (y-o-y) } & \multicolumn{2}{|c|}{ CPI Inflation ( y-o-y) } & \multicolumn{2}{|c|}{ Months Lead (-) / Lag (+) } \\
\hline $\begin{array}{c}\text { PEAK } \\
\end{array}$ & TROUGH & PEAK & TROUGH & PEAK & TROUGH \\
\hline $\begin{array}{l}\text { June } 1998 \\
\text { April } 2001 \\
\end{array}$ & June 1999 & $\begin{array}{l}\text { September } 1998 \\
\text { February } 2002\end{array}$ & March 2000 & $\begin{array}{l}-3 \\
-10 \\
\end{array}$ & -8 \\
\hline & & & & In Months & In Quarters \\
\hline & & & $\begin{array}{l}\text { Mean } \\
\text { Stand. Deviation }\end{array}$ & $\begin{array}{c}-7.0 \\
3.6 \\
\end{array}$ & $\begin{array}{c}-2.3 \\
1.2 \\
\end{array}$ \\
\hline \multicolumn{2}{|c|}{ Nominal M1 (y-o-y) } & \multicolumn{2}{|c|}{ CPI Inflation ( y-o-y) } & \multicolumn{2}{|c|}{ Months Lead (-) / Lag (+) } \\
\hline PEAK & TROUGH & PEAK & TROUGH & PEAK & TROUGH \\
\hline $\begin{array}{l}\text { August } 1998 \\
\text { December } 2000\end{array}$ & June 1999 & $\begin{array}{l}\text { September } 1998 \\
\text { February } 2002\end{array}$ & March 2000 & $\begin{array}{c}-1 \\
-14 \\
\end{array}$ & -8 \\
\hline & & & & In Months & In Quarters \\
\hline & & & $\begin{array}{l}\text { Mean } \\
\text { Stand. Deviation }\end{array}$ & $\begin{array}{c}-7.7 \\
6.5 \\
\end{array}$ & $\begin{array}{c}-2.6 \\
2.2 \\
\end{array}$ \\
\hline
\end{tabular}

It is apparent from the graph that the three series move in concordance, suggesting positive relationships between them. This concordance in movements, however, seems to take place with some lags. Table 3 summarizes the lead-lag profiles of the three series after the floating of Rp/USD exchange rate. There are three episodes of turning points in each series $^{24}$. Overall, the dates of the turning points of the annual growth of nominal M1 and the turning points of the annual changes of Rp/USD differ only by on average $-0,2$ quarter $+/$ 1 quarter standard deviation. Thus the movements of the two series could lead or lag each other by 1 quarter and overtime they tend to coincide with each other. However, the movements in the annual changes of $\mathrm{Rp} / \mathrm{USD}$ exchange rate and the movements in CPI inflation are not coinciding. It is calculated in table 3 that the turning points of the annual changes of Rp/ USD lead the turning points of CPI inflation by on average 2,3 quarters with $+/-1,2$ quarters standard deviation. Hence the former could lead the later by at least 1 quarter earlier or at most by 3,5 quarters. To close the nexus, we see how the movements of the annual growth of nominal M1 lead the movements of CPI inflation. As reported in table 3, the former lead the later by on average 2,6 quarters with a $+/-2,2$ quarters standard deviation. Thus CPI inflation could move immediately after there are changes in the annual growth of nominal M1 or it could lag behind by at most 4,8 quarters. These patterns further strengthen the hypothesis that there could be two different channels in which the annual growth of excess nominal

24 The detail results on the Bry-Boschan algorithms and markov regime switching regressions are available upon request. 
narrow money could affect inflation. These channels would be (1) the long direct channel of too much money chasing too few goods, and (2) the shorter indirect channel via the import prices pass through effects, as has been explained previously ${ }^{25}$.

Third, the observed lags in the effects of the annual growth of excess narrow money on inflation could be due to several factors, but most importantly to the heterogeneous capacity of suppliers to process information about the presence of monetary disequilibria in the economy. The first group of suppliers has enough financial resources to collect and process all the available monetary and economic information and excel in analyzing the inflation process. This type of suppliers is identified by Robert Lucas from the New Classicist as the rational agents who are capable of constructing a perfect foresight forecast of inflation, using all the available information including the patterns of the central bank's policy behaviours without making any systematic errors ${ }^{26}$.

The second type of suppliers is similar to the Lucas type agents but they are more "human" in nature. They are capable of collecting and processing information, but they are not able to make a perfect foresight forecast. The best they can do is to make a type of conditional forecast of inflation utilizing all the available monetary and economic information relevant for explaining inflation process. They know about inflation and the monetary sources of inflation and continuously monitor the development in the monetary disequilibria that exist in the economy. In other words, they also carefully scrutinize the pattern of central bank's past behaviours and performance in controlling the disequilibria. They are different from the Lucas type in the sense that they only learn gradually about the true model of the economy and the time variations in the parameters of their conditional economic models of inflation. Hence, this type of agents is rational but their rationality is limited by their human capacity to learn as argued by Thomas Sargent. In reality, these agents may include those sophisticated professional inflation forecasters in the market ${ }^{27}$.

However, there is also a group of suppliers who does not have enough financial resources to collect and process information. For this group of agents, information is simply

25 With respect to the money - exchange rate - inflation nexus in post crisis Indonesia, readers can also consult the recent works of Rajaguru and Siregar $(2002 \mathrm{a}, 2002 \mathrm{~b})$ who have also pointed out the possible presence of such a nexus in Indonesia since 1997.

26 For a review on Robert E Lucas' ideas about agents' inter-temporal economic choices and behaviours readers may consult Chari (1999) and Sargent (1996). A pleasant commentary on Lucas type agents with rational expectations can be found in Maddock-Carter (1982).

27 Sargent identifies the economic modellers in most successful and credible central banks, such as the Federal Reserves, as the type of people whose rationality is limited by their human capacity to learn. Accordingly, we can easily extend Sargents' identification to the sophisticated professional inflation forecasters in the market as well. They are agents who conduct adaptive forecasts but their empirical models use all the available information and take into account the reaction function of the central bank. For the expositions of the Sargent type modellers see for instance Sargent (1999). On the relationships between agents formation of expectations and inflation see Sargent (1992). 
too costly to collect and to construct a sophisticated conditional forecast of inflation is beyond their financial capacity. They are not aware of the central bank's monetary targets, policy rules, and inflation control framework. They are also not well acquainted with economic indicators such as monetary aggregates, GDP growth, CPI inflation, and so on. This type of suppliers could be the type of suppliers in the traditional markets or bazaars. This is the classical type of suppliers as envisioned by David Hume and later by Milton Friedman ${ }^{28}$. They tend to lag behind in their inflation forecasts since they conduct only naïve or at best adaptive forecasts using only the day-to-day market observations on past prices or their "inner guts' feelings" on the likely movement of the general prices in the future.

If the Lucas or Sargent type agents are the dominant type in the market place, then there would be a short lag in the effects of excess money growth on exchange rate or inflation. In fact if the presence of the Lucas type is stronger in the market, then exchange rate and inflation may lead excess money growth, and not vice versa. This is because by assumption, the Lucas and Sargent type agents look at also the policy reaction function used by the central bank and the past behaviours and performance of monetary policy. As a result, when they suspect there is a high probability that the central bankers will deviate from their commitment to promote monetary and price stability in the future, then they will increase their inflation expectations ahead of time before the effects of excess money on inflation actually happen. As they increase their inflation expectations, they will adjust their supply prices upward and their planned productions downward at once. Hence the increase in actual inflation will materialize faster, even before the actual excess money completes its pipeline effects. The consequence of this is that inflation will rise more persistently if the central bank is indeed deviating from the commitment to promote monetary and price stability.

On the other hand, if the Friedman type suppliers prevail in the market, then due to their limited ability to forecast and their ignorance about the central bank's past policy behaviours, they tend to lag behind in their prices and output adjustments. This is because the only variable they look at in predicting the future prices is the past realizations of prices in the market. This crude type of forecasting results in systematic errors and as a consequence Friedman type agents are always late in realizing the shifts in the trend of the general price movements. As they lag behind in their price adjustments, inflation will increase or decrease more slowly.

Looking at the short and even immediate effects of the excess money growth on Rp/ USD exchange rate in post crisis era, then it could be said that agents in the financial market in Indonesia are sophisticated. It is quite plausible to equate them with at least the Sargent

28 Friedman type agents can conduct adaptive forecasting as well, yet their information set is limited only to the development in past prices. Using the expectations augmented Phillips Curve as the basis of analysis Friedman implicitly suggests his type of agents in Friedman (1977). See also Friedman (1961). 
type agents. Moreover, by looking at the quite long and variable lag effects of excess money on inflation before, during and after monetary crisis, and a shorter lag effect of the exchange rate on inflation during and after monetary crisis, then it could be said that a part of the agents in the goods market in Indonesia is not as sophisticated as those in the financial market, but a part of them is as sophisticated. Consequently, the variations in the level of sophistications of agents in the financial and goods market could cause the movements of inflation tend to be more persistent or exhibit a high inertial component ${ }^{29}$. This is because inflation could increase faster when: (1) the money-exchange rate nexus are transmitted into the domestic prices via the import price pass-through effects, and (2) the central bank is expected to deviate from its commitment to promote monetary and price stability ${ }^{30}$. But these are only the initial pick up on inflation. As agents' pessimistic outlook on inflation is validated by a non-committal conduct in monetary policy, then there will be additional inflationary pressures in the goods market in due time, as the pipeline effects of too much money chasing too few goods take its actual bites on the market.

\section{THE EFFECTIVENESS OF A MONETARY TARGET AND POLICY COMMITMENT}

\section{The Controllability of Narrow Money}

Given the above plausible type of economic relationships in Indonesia since 1980 then a rule-based conduct of monetary policy to avoid the presence of excessive monetary disequilibria, such as the base money targeting, will be fruitful in curbing inflationary pressures and stabilizing the nominal exchange rate in post crisis Indonesia. This is because even if BI cannot directly control the nominal cash component of base money for it is demand driven, yet it can indirectly influence it by manipulating the opportunity cost of holding nominal cash balance or the level of nominal interest rate in the economy. We will discuss this proposition in a greater detail below.

First of all, what could be the trigger for the demand driven decrease or increase in the annual growth of nominal cash that correlates to money being driven into and out of the financial intermediaries? The answer that we propose is the opportunity cost of holding money as suggested by Milton Friedman $(1956)^{31}$. In simple words, this opportunity cost is measured as the nominal interest rate that a person could earn when putting his/her excess cash at the financial intermediaries as opposed to holding the cash and using it to purchase goods or services. Thus when the nominal interest rate is increasing, we could expect this

29 This is quantified by the degree of serial correlations in the CPI inflation series.

30 Similar effect can arise when the government is expected to increase the administered prices.

31 See also Friedman (1966). 
Graph 3. The Relationship Between The Turning Points of the Nominal

1 Month Time Deposit Rate (Inverted) and Cash Disequilibria since 1981

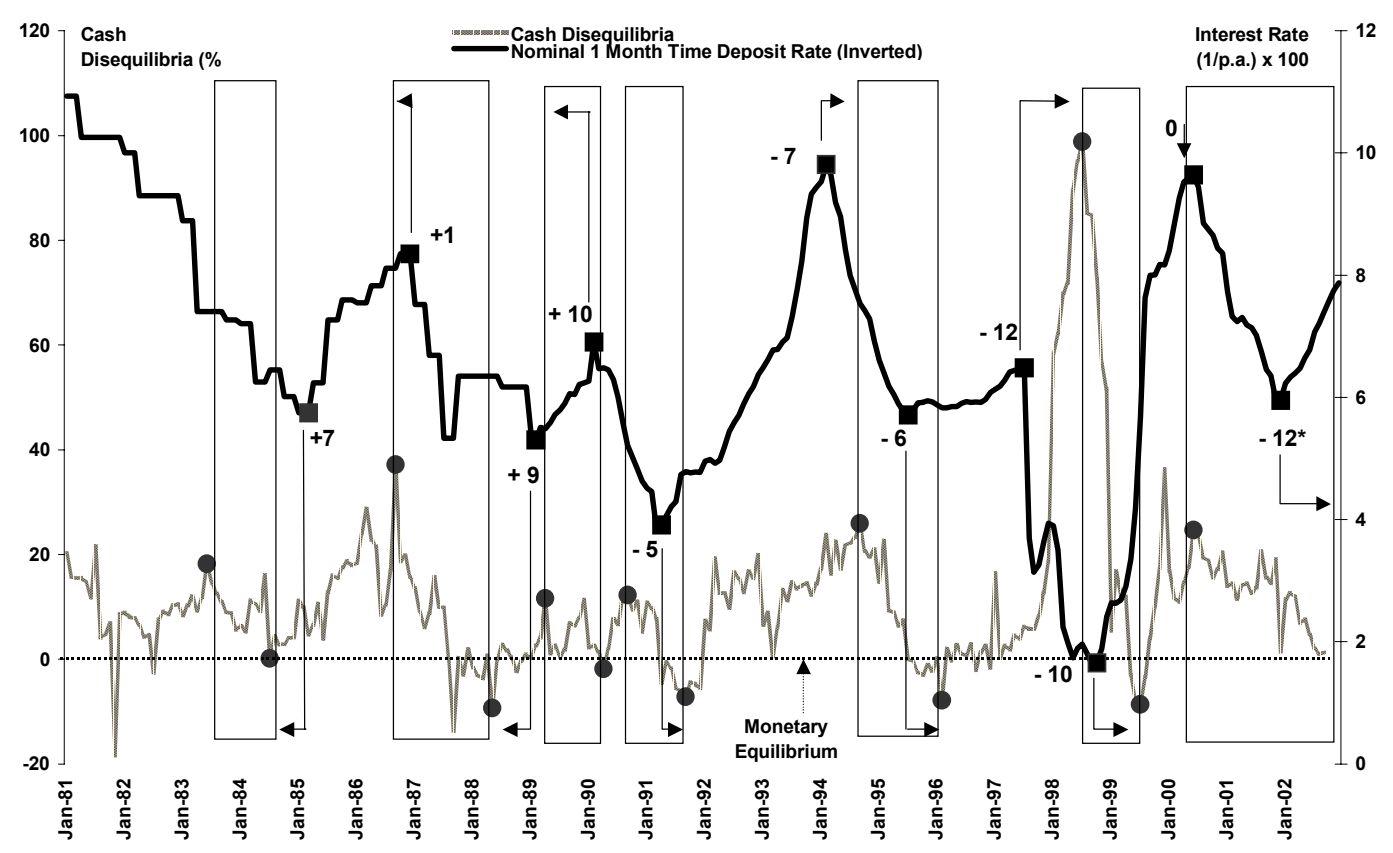

person would hold less nominal cash and prefer putting his/her money in the commercial banks for instance, or other forms of assets that yield interest. But when the interest rate is declining, then he/she would prefer using his/her nominal cash to purchase consumable goods. Yet, agents could also shift their excess cash to assets denominated in foreign currency (flight to currency). This could happen when the expected depreciations and inflations embodied in the domestic interest rate relative to foreign are too high (i.e. via the international Fisher parity $)^{32}$.

Graph 3 illustrates the plausibility of the opportunity cost hypothesis in Indonesia. In the graph we have depicted the annual growth of excess nominal cash above its real need for consumption spending (cash disequilibria). In other words, cash disequilibria are simply the annual growth of nominal cash minus the annual growth of domestic households' consumption spending as depicted in graph $1 \mathrm{a}$ and $1 \mathrm{~b}$. The turning points of cash disequilibria are marked by the circle dots. The boxes represent the downturn phases of cash disequilibria from peaks to troughs. We also plot the inverse [(1/p.a.) x 100] of the 1-month nominal time deposit rate at the commercial banks. Its turning points are marked by the square dots. Thus the increase / decrease in this inverted rate corresponds to the decrease / increase in the non-

32 For a standard exposition see for instance Rodseth (2000, p 9-35, p. 204 - 211). 
inverted rate. Accordingly the peak / trough in the inverted rate refers to the lowest / highest value in the non-inverted rate. This way we can ask questions such as: (1) whether the peaks in the inverted rate (or lowest values in the non-inverted rate) correspond to the peaks (highest values) in the annual growth of cash disequilibria, and (2) whether the troughs in the inverted rate (or highest values in the non-inverted rate) correspond to the troughs (lowest values) in the annual growth of cash disequilibria. If the answers of these two questions are affirmative then we could say that the two series exhibit a negative relationship, and hence the opportunity cost hypothesis is plausible.

As can be observed from graph 3 the two series move in concordance suggesting a negative relationship. The peaks / troughs in the inverted 1 month nominal time deposit rate (which represent the lowest / highest values in the non-inverted rate) always correspond to the peaks / troughs in the annual growth of cash disequilibria. One can also observe that overall this relationship is not prompt. Since 1990, the movements in the 1-month nominal time deposit rate have led the movements in the annual growth of cash disequilibria. However, before 1990 the former clearly lagged the later. The leading relationship from the nominal 1 month time deposit rate to cash disequilibria since 1990 has been on average 7,5 months with a +/-2,3 months standard deviation. Accordingly the former could lead the later by at least 5,2 months or at most 9,8 months. Therefore we can argue that since 1990 there has been strong evidence that could lend support to the opportunity cost hypothesis ${ }^{33}$.

Moreover, we can roughly estimate the length of the lag in the effects of SBI policy on inflation. We have calculated above that on average the movements in the inverted nominal 1 month time deposit rate lead the movements in the annual growth of cash disequilibria by 7,5 months or approximately 3 quarters. Thus we could expect the movements in SBI rate to have the same lead pattern to the annual growth of nominal cash. Meanwhile from earlier discussions we know that the annual growth of nominal cash lead CPI inflation by on average 8,5 months or approximately 3 quarters. Adding up these lead patterns yields the estimate of the lag effect of the SBI rate policy on inflation, which is roughly 6 quarters on average or 1,5 years. This long lag effects is quite normal considering the same policy lag patterns that arise in other countries ${ }^{34}$.

Furthermore, it is informative at this stage to have a brief look at the strength of the nominal short-term interest rate in affecting agents' inter-temporal decisions to hold excess

33 It could also be argued at this stage that this hypothesis has been plausible only after the banking system had been fully deregulated in late $1980 \mathrm{~s}$. A possible explanation for this phenomenon is prior to the banking system deregulation, people did not suffer much from opportunity cost of holding excess cash because there was less alternative to holding excess cash in the first place.

34 Readers may consult the websites of most central banks in OECD and inflation targeting countries to confirm this assertion. Most recently, the European Central Bank (ECB) has also argued that the effect of its monetary policy on inflation in Euro area comes to pass only after some long lags (see the ECB website at www.ecb.int) 
narrow money. From the results of the money demand estimation in the appendix, we could say that agents' decisions to hold excess M1 are sensitive to the movements in the short-term nominal interest rate (measured by the 1 month nominal SBI rate). The sum semi-elasticity of M1 disequilibria to changes in 1 month nominal SBI rate is approximately in the range of 0,42 to $-0,82$.

Meanwhile, a crude illustration on the elasticity of cash disequilibria to changes in 1 month nominal time deposit rate at commercial banks also point to the same impression. Graph $4 \mathrm{a}$ and $4 \mathrm{~b}$ depict the scatter plots of the two series since 1990 taking into account the lag effects in each episodes as calculated in graph 3. It must be noted that we have excluded one episode in our scatter plots, namely the episode during the currency crisis in which the deposit rate led cash disequilibria by 12 months. This is done because it is clear from the graph that the upward phase in the inverted rate from late 1995 to late 1997 was incomparable in magnitude to the upward phase of cash disequilibria from early 1997 to mid 1998. In other words, we argue that the jump in cash disequilibria during this episode was caused by factor other than the opportunity cost to hold nominal cash balance. It can be reviewed from the two graphs that the elasticity during the crisis stabilization period was higher than the pre-crisis era. However, the elasticity during the post crisis era is clearly higher than the pre-crisis and the crisis stabilization period. Such crude evidence suggests that agents' holding of excess cash has become more sensitive in post crisis era. If this non-linearity is indeed the case, then

\section{Graph 4a. The Pre-Crisis Elasticity}

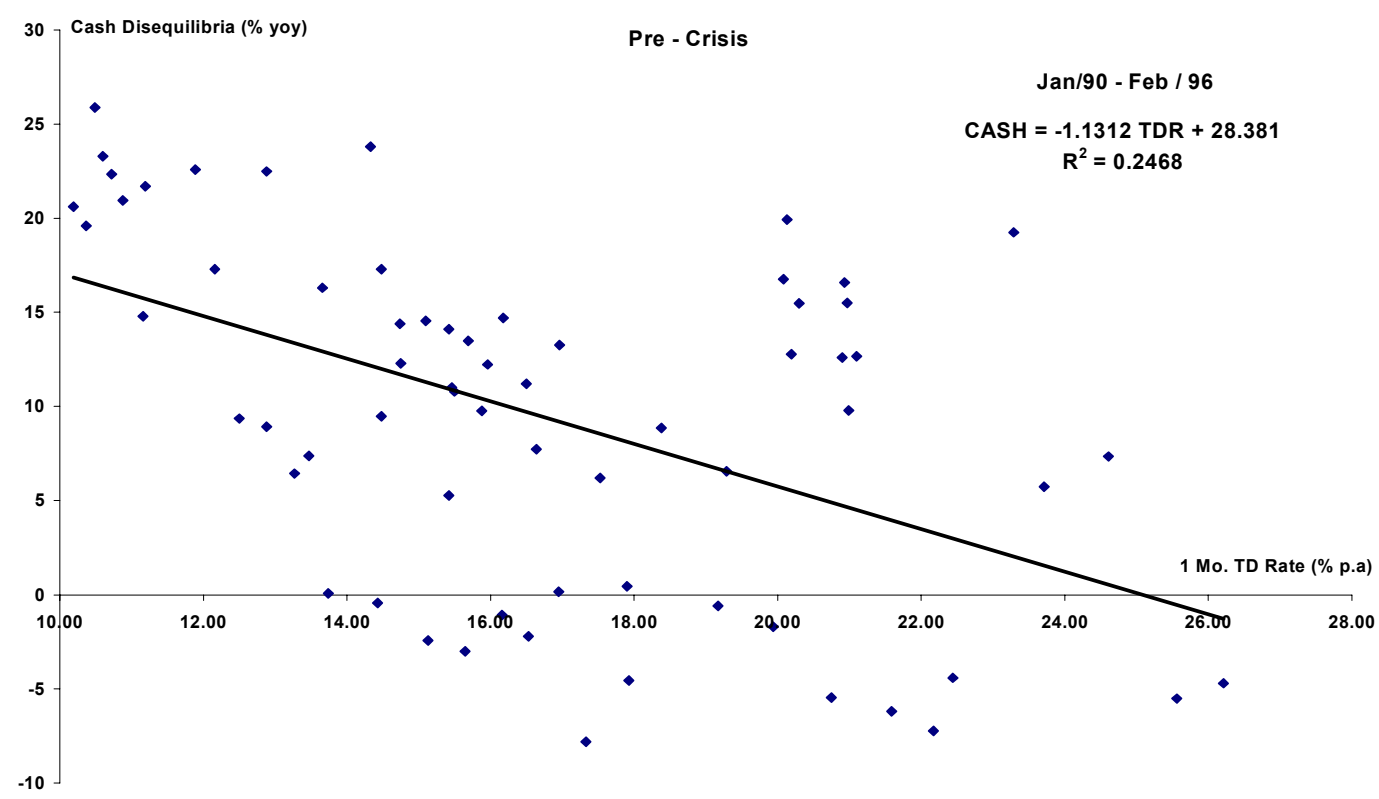


Graph $4 \mathrm{~b}$. The Crisis and Post Crisis Elasticity

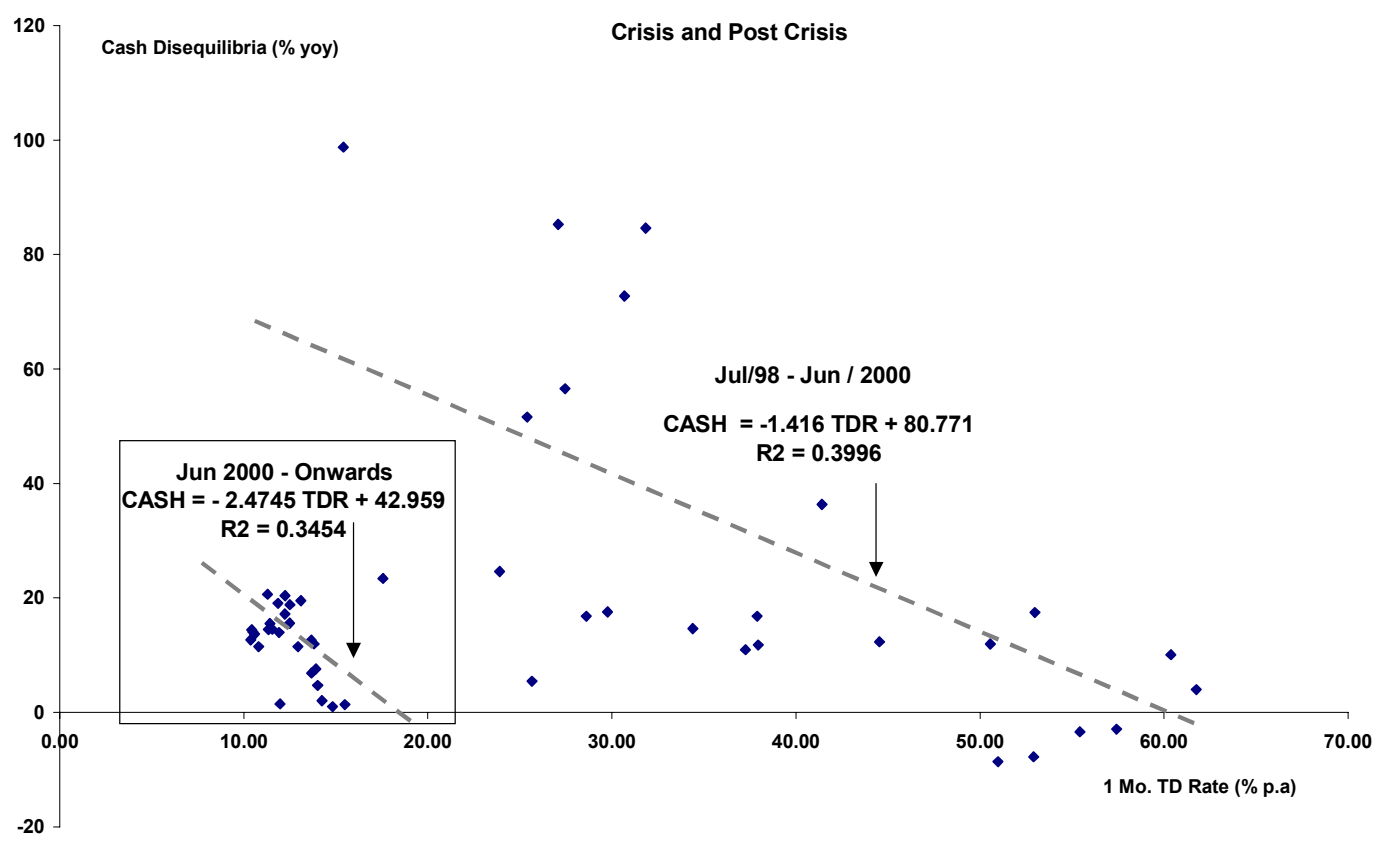

it could be argued further that BI could run into a higher risk of loosing control over nominal narrow money growth when the SBI rate is declining too low too fast in post crisis Indonesia.

Given the plausible existence of economic relationships such as described above, then the base money-targeting framework can be effective in curbing the inflationary pressures and at the same time supporting the stabilization of the Rp/USD exchange rate in post crisis Indonesia. This is because first of all, by promoting a steady growth of nominal narrow money according to its real need, monetary policy is avoiding monetary disequilibria inducing inflationary pressures in the goods market. Hence monetary policy is preemptively attacking the pipeline effects of excess money on price inflation in the goods market.

Second, with a money growth target, monetary policy will be geared towards a vigilant SBI policy. At the margin, a strong stance in SBI policy will be reflected in the financial market as a high opportunity cost of holding excess nominal cash balance. Such an effect will increase BI's ability to contain the flows of nominal cash out of the financial intermediaries. Accordingly, when there is a plausible positive correlation between excess nominal cash and $\mathrm{Rp} /$ USD exchange rate, then a strong stance in SBI will be fruitful in containing the exchange rate depreciation and supporting the appreciation when expectations in the market are shifting. This assertion is clarified further below. 
Graph 5 depicts the evolutions of the annual growth of nominal narrow money defined in terms of base money, cash, and M1, and the development in 1-month nominal SBI rate and 1-month nominal time deposit rate at the commercial banks. From graph 5 it can be seen that the annual growth of nominal cash balance and M1 were in excess between late 1999 until mid 2001. Corresponding to these excesses is the annual growth of nominal base money that was above its assigned growth ceiling ${ }^{35}$. One reason can be attributed to these phenomena. As documented in all of the MEFPs signed between mid 1999-end 2000, one will notice that the policy discussions within those documents put a strong focus on maintaining a low level of nominal interest rate in addition to maintaining the base money growth $\operatorname{target}^{36}$. This is because there was a growing concern, as reflected in the documents, that a high nominal interest rate will jeopardize the prospect of growth recovery and impose a higher burden on the costs of bank restructuring process. Accordingly, additional objective was assigned to monetary policy, namely to guide the nominal interest rate down cautiously.

However, the assignment given to monetary policy to reduce the nominal interest rate entailed a risk. Even though inflation was declining in 1999, yet its expectations had not been

\section{Graph 5. Nominal Narrow Money Growth and Nominal Short Term Interest Rates (Post Crisis Period)}

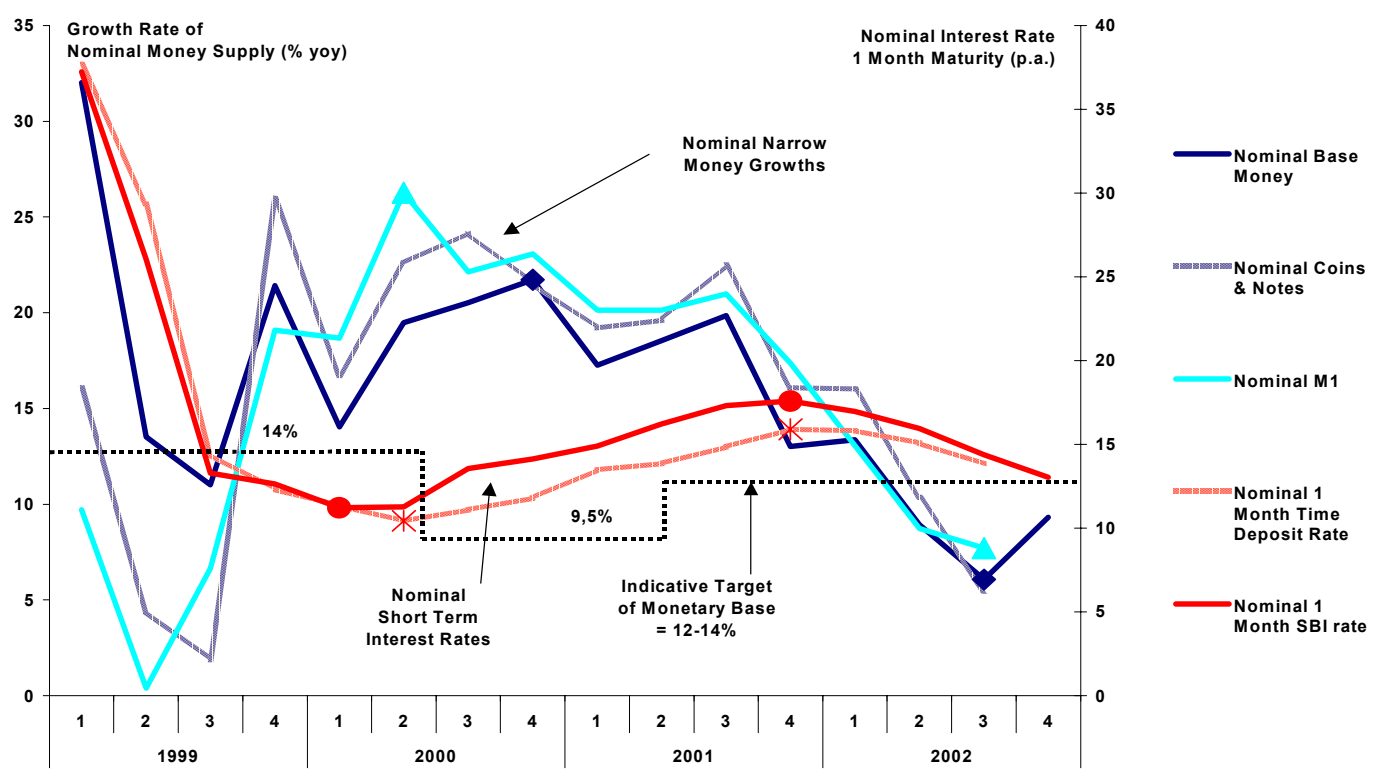

35 MEFP signed in March 161999 assigned a base money target of 14\% p.a.. This target was revised downward to 9.5\% p.a. in the MEFP signed in January 202000.

36 See MEFP signed in July 22 1999, January 20 2000, July 31 2000, and September 72000. 
anchored $^{37}$. As a result, a further decline in SBI rate even when it was cautiously done could result in the lowering of BI's ability to control the annual growth of nominal cash balance. This lower controlling ability was risky, especially when cash balance is demand driven, agents are rational, and the excess nominal cash can easily be shifted into USD in the event of high political uncertainties. For instance, in the brink of a political election in late 1999, the level of SBI rate and the short term nominal interest rate in the market were already low especially since mid 1999. This induced rational agents to withdraw cash out of the financial intermediaries and use their nominal cash holdings for speculations in the Rp/USD market to hedge against the election uncertainties. The same type of speculation re-emerged in mid 2000 when market was growingly dissatisfied with the policy choices of the newly elected administration. Nevertheless, graph 5 shows that BI correctly took the necessary policy steps to contain the monetary disequilibria by flattening the SBI rate in Q1/2000 and started to continuously increase its SBI rate since Q2/2000. This suggests that BI entirely disregarded the perilous assignments written in the MEFPs to guide down the interest rate cautiously ${ }^{38}$.

The impact of the uncertainty driven excess nominal narrow money growth (represented by the M1 disequilibria) in 2000 was directly felt in the imported goods market ${ }^{39}$. Graph 6 gives a pictorial aid on this point. As can be seen from the graph that after a short lag, the annual changes in Rp/USD move in tandem with the excess M1 growth. As Rp/USD depreciated, the pass-through effects on the prices of imported goods were immediate and as a result inflation began to increase since mid 2000. As excess narrow money grew further throughout year 2000 until the first half of 2001 and continuously fuelled the rupiah depreciations, the SBI policy became less potent in containing the monetary disequilibria unless there was a continuous increase in SBI to match the prevailing expected depreciations and inflation in the market. Again, graph 5 shows that BI correctly took the necessary policy steps to contain the expected depreciations and inflation by more vigorously increasing its SBI rate since Q1/2001.

The effect of the continuous increase in SBI rate since Q2/2000 was a gradual slow down in the growth rate of excess nominal narrow money balance since mid 2000 as the outflows of cash out of the financial intermediaries were contained by the corresponding increase in the short term time deposit rate (Graph 5). When the new administration took office in August 2001, the market gave a vote of confidence causing rupiah to appreciate

37 In our view inflation expectations are anchored if the actual level of inflation has been maintained at a low and stable rate for at least two policy lag cycles. Since our earlier rough estimate suggests that the policy lag from SBI to inflation is on average 6 quarters, then two policy lag cycles are approximately 3 years.

38 Since the Central Bank Act 23/1999 grants BI with instrument and goal independency status, then such a decision reflects also a sound and prudent decision taken by an independent central bank.

39 As before, M1 disequilibria is defined as the excess growth of nominal M1 above the real growth of domestic households' consumption spending. The later could also be viewed as the real demand for M1. 
Graph 6. The Relationships Among Excess M1, Rp/USD,

Import Prices, and CPI Inflation (Post Crisis)

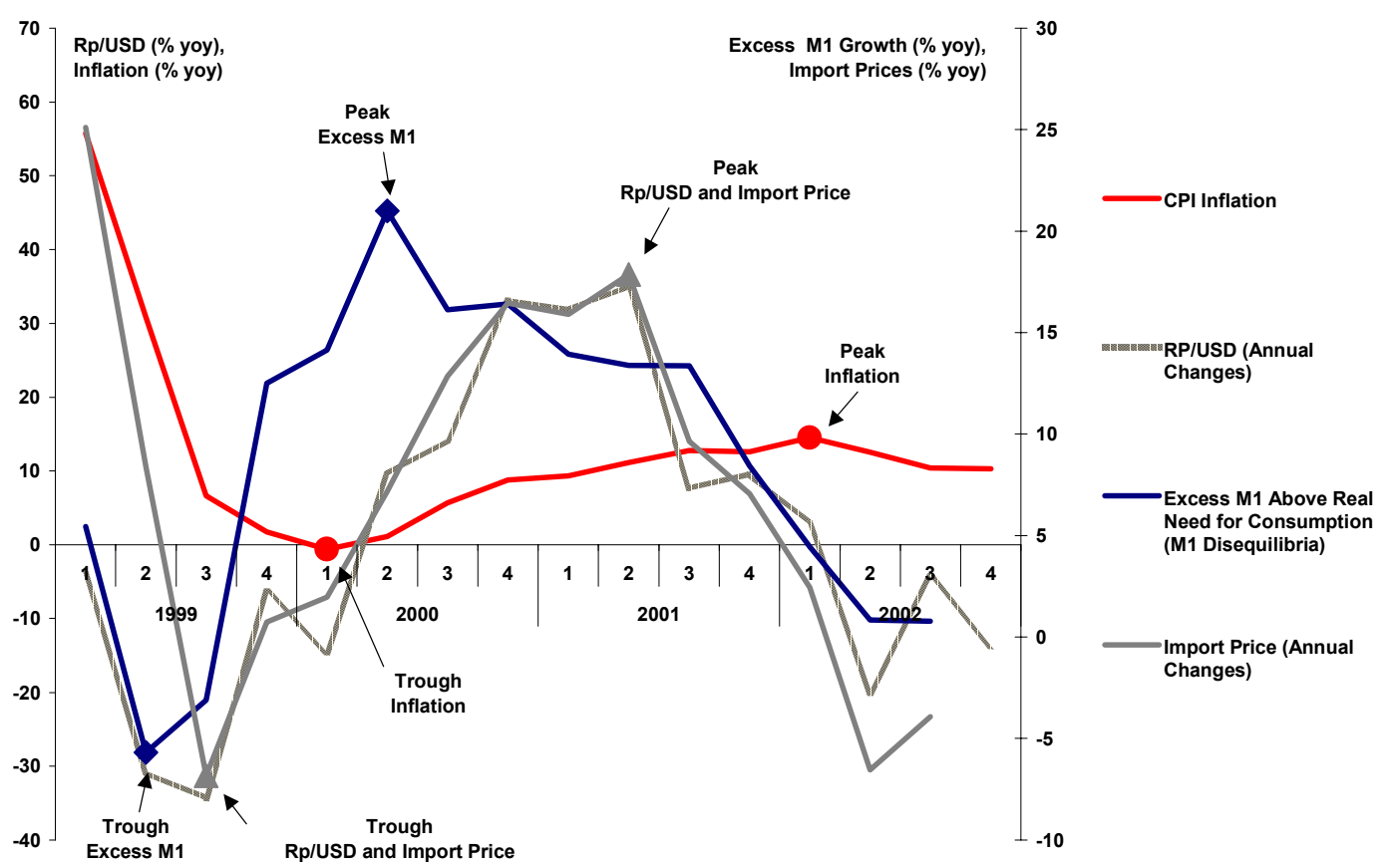

(Graph 6). By then, the already slowing down annual growth of excess nominal narrow money supported and sustained this shift in market expectations, causing the rupiah to appreciate further (Graph 6). With the strengthening of the expected rupiah appreciations, the already high SBI rate became more potent in re-absorbing the excess cash back into the financial intermediaries (Graph 5). As a result we can see that the excess growth of nominal narrow money declined faster since mid 2001 and so did the USD (Graph 5 and 6).

\section{The Contribution of an Overriding Commitment}

The decline in the annual growth of excess nominal narrow money balance continued well after 2001. One reason that can be attributed to this was BI's overriding commitment to reduce the excess base money growth, stabilize the Rp/USD exchange rate, and curb the inflationary pressures further in 2001. This assertion is supported by the fact that since mid 2001 the formulation and conduct of monetary policy had been strongly focused on achieving and maintaining price stability in post crisis Indonesia. The MEFP signed in August 272001 clearly stated that monetary policy will be set consistent with the inflation target and a strong base money policy will be established to contain the inflation pressures in the economy. An 
explicit and quantifiable inflation target was set at $9-10 \%$ by end of 2001. The MEFP also prescribed that the conduct of monetary policy shall be guided by a rule defined in terms of a base money growth ceiling. This type of arrangement was reasserted in the MEFP signed in December 31, 2002 where a plan was made to gradually reduce nominal base money growth from $20 \%$ to $12-14 \%$ by end of 2002 . This plan was accompanied by a restatement of the previous pre-announced commitment to push inflation down to a 9-10\% range. All of these ex-ante pre-announced plans were carried out wholeheartedly ex post, suggesting an overriding commitment to promote monetary and price stability. In graph 5 it is shown that even though the exchange rate was appreciating, BI maintained a very vigilant reduction in the SBI rate throughout 2002. This contributed to the significant decline in the annual growth of nominal base money since the beginning of 2002 as the excess nominal cash was reabsorbed back into the financial intermediaries. By mid 2002 the annual growth of nominal base money had fallen into its indicative target ceiling, signifying the disappearance of monetary disequilibria in the economy. As base money fell, inflationary pressures began to cease and decline. By the end of 2002, inflation was only slightly above its pre-announced target. In the mean time, all definitions of excess nominal narrow money balance were on their non-inflationary path in 2002 as the growth rate of base money consistently below the $12-14 \%$ ceiling since Q2/ 2002 (see graph 5 and 6).

The decline in inflation in 2002 could be expected to continue in 2003 for the price adjustments in goods market may have not been fully completed, due to the long lags in the effects of downward adjustments in the nominal cash and M1 on inflation, as we have discussed in section II.

The above discussions signify the fact that given the plausible existence of the monetarist type economic relationship in Indonesia, when monetary policy is conducted with an overriding commitment to promote monetary and price stability, then the results could be fruitful in bringing about exchange rate stability and curbing inflationary pressures in post crisis Indonesia. Moreover, the discipline conduct of monetary policy in 2002 could also add another strong precedent in the market that monetary policy is seriously committed to its pre-announced price stability objective. But market participants may need more precedents before their expected inflation can be properly anchored. Hence, we argue that the overriding commitment to pursue the price stability objective should be strengthened in 2003 so that BI can gain more credibility premium in its attempt to anchor the inflation expectations in post crisis Indonesia.

One additional lesson could be learned. Given the rationality of agents in the financial market and the sensitivity of excess nominal cash holding to changes in short term nominal interest rate, then it is necessary for BI to stay vigilant in its policy stance on the 1-month 
nominal SBI rate in post crisis Indonesia. This vigilant stance must be maintained until there is a clear sign that inflation expectations have been anchored ${ }^{40}$. This careful consideration on SBI must be asymmetrical in the sense that during a decline in inflation, the SBI rate must not decline too low too fast ${ }^{41}$.

As final remarks, a proposal for a reckless reduction in SBI rate, especially if it arises from political pressures to promote objectives other than price stability must be abandoned for this will lower BI's ability to conduct proper control over nominal narrow money, especially nominal cash in circulation. One possible objective other than price stability that could be demanded from $\mathrm{BI}$ is the promotion of long run economic growth via low interest rate policy. This type of myopic policy should be rejected because the long run real economic growth is not the realm of monetary policy ${ }^{42}$. Conceptually it is the realm of the structural supply side policy that must be conducted by GOI instead of BI as we have touched briefly before ${ }^{43}$. The best contribution that $\mathrm{BI}$ can provide for sustaining economic growth recovery in post crisis Indonesia is by promoting monetary and price stability. When the prices in the goods market are stable, then there is a good chance that inflation expectations will be anchored at a low and stable level. Since inflation expectations are the main component of the nominal interest rate $^{44}$, then interest rate can be brought down naturally without any artificial (political) attempts to lower it when inflation has been maintained at a low and stable level for sometimes ${ }^{45}$. A failure to maintain control over the growth of excess narrow money balance when inflation has not been properly anchored could be hazardous for the economy in the long run. This is because to recapture the excess liquidity, the SBI rate must be increased again high enough to match the expected depreciations and inflation in the market. Thus, it is more beneficial if monetary policy is conducted independently and in a discipline manner by an inflation-averse central bank. By being discipline monetarily, BI will lower the risk of triggering a rise in monetary disequilibria that could induce a boom-bust cycle in the nominal interest rate and jeopardize the prospect of sustainable economic recovery in post crisis Indonesia.

\section{ENHANCING THE OVERALL MONETARY POLICY FRAMEWORK}

Despite the initial success of the base money targeting framework, there are rooms in which BI's overall inflation control framework could be enhanced further. We will argue below that improvements could be attained if in formulating its monetary policy decisions, BI

\footnotetext{
40 See footnote no. 37.

41 Borrowing from Allan Greenspan: "It is always better to err on the safe side".

42 See the weak exogeneity status of real consumption growth in the appendix. .

43 See page 9 .

44 Fisher relation defines nominal interest rate as the real interest rate plus the expected inflation.

45 For instance, a low and stable inflation has been maintained for at least 3 years. See footnote 37.
} 
formalizes the transparent use a full set of information criteria. This type of strategy has been employed by the European Central Bank (ECB).

From the discussions in previous sections we have learned that even though a part of the agents in the goods market in Indonesia could be characterized as less sophisticated, yet those in the financial market are. This might have contributed to the observed persistence of inflation and the upward bias in inflation expectations in Indonesia. Given these heterogeneous learning capacities in the market, it is always a safer route for a central bank that is fighting inflation to deliberately assume that all agents are rational and capable of conducting sophisticated conditional forecasts of inflation using all the available information including the patterns of central bank's past policy behaviours ${ }^{46}$. The adoption of such an assumption implies that when formulating its monetary policy decisions, it is necessary that the central bank also behaves like the sophisticated agents, namely by utilizing all the available information that are relevant in explaining inflation expectations (the full information criteria). By doing so the central bank's policy analysis and discussions will win more trust among those well informed agents in the private sectors. Winning the trust of agents in public policy discussions is important, especially when it is agents' inflation expectations that the central bank is trying to anchor. In other words, if agents believe that the central bank inflation assessments are highly trustworthy and credible, then this is the first step in winning further their vote of confidence on the central bank's ability to tackle the naughty issue of inflation bias and persistence.

Accordingly, the credibility of BI's inflation assessments is determined by the fullness of information set used in analysing the risks to price stability in Indonesia. Hence, if BI uses only a less than full information set, then agents will not believed BI's ex-anteinflation outlook, and will always doubt the ability of BI in conquering inflation in post crisis Indonesia. As a consequence, agents' inflation expectations will always be above the inflation target set by $\mathrm{BI}$, reflecting expectations that have not been properly anchored. If this continues then agents' price adjustments in the market will always be biased upward and the actual inflation bias will continue to persist in post crisis Indonesia.

Motivated by the above propositions, we will discuss the ECB type strategy in formulating monetary policy below. One of the main characteristics of the ECB type strategy is its use of a formal and transparent full information criteria in formulating monetary policy. Below is a brief review of the strategy.

The monetary policy decision-making process of the ECB can be categorized as a structured and transparent full information decision making process illustrated in Diagram

46 Again see footnote 41. 
1 below. In the bottom of the diagram is the input of the decision making process, namely all the relevant economic information used to assess the risks to price stability in the Euro area. These economic information are broken down into two large types of information, namely (1) the information that can lead to the monetary analysis of inflation or the first pillar of the strategy, and (2) the information that describe the non-monetary aspects of inflation or the second pillar of the strategy. The analysis in the first pillar is related to the monetary analysis of inflation [such as done in Milton Friedman and Anna J. Schwartz $(1963,1982)]$. Two dicta that are attributed to this type of analysis are (1) inflation is always and everywhere a monetary phenomenon and (2) the effects of excess money growth on inflation come to pass only after some long and variable lags as we have discussed before. The analysis in the second pillar is related to non-monetary theories of inflation, such as the New Keynesian output gap-inflation nexus, the traditional Keynesian demand pull-cost push, the structural hypothesis, and so

Diagram 1.

Schematic Presentation of the ECB Two Pillars Strategy ${ }^{47}$

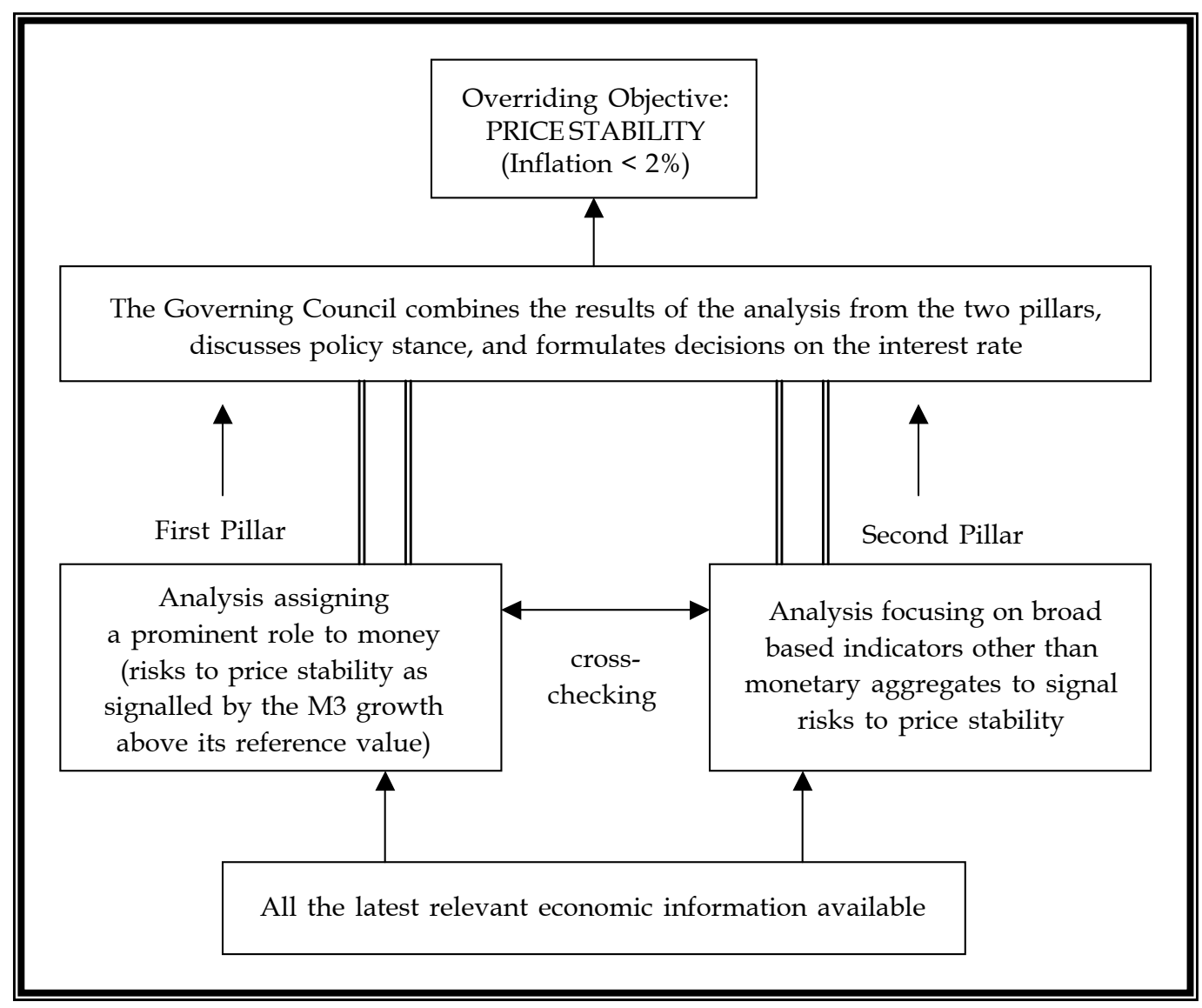

47 This chart follows closely one in the ECB Monthly Bulletin, November 2000, p. 39 
on. In other words, while the first pillar uses mainly money as the variable that explains inflation, the second pillar abandons money altogether and use instead a wide range of nonmonetary indicators to explain the inflation process.

Embodied in the first pillar of the ECB monetary policy strategy is the use of the reference value of $\mathrm{M} 3$ as a guide for monetary policy decisions. M3 is the broadest monetary aggregate constructed for the Euro area. It consists of currency in circulation, overnight deposits, deposits with agreed upon maturity up to 2 years, deposits redeemable at notice up to 3 months, repurchase agreements, money market fund shares/units and money market paper, and debt securities up to 2 years.

To date the reference value of $\mathrm{M} 3$ is at 4,5\%. This figure is obtained using the quantity theory of money and its corresponding demand for money function. For the Euro area, estimates of the demand for money function reveal that there exists a stable demand for real money balance in terms of M3 aggregate [Brand-Cassola, (2000), Coenen-Vega (1999)]. It has also been found that M3 aggregate leads inflation in the Euro Area [Altimari (2001)]. With these findings the ECB argues that the velocity of money is stable but has a trend decline about $0.5-1 \%$ p.a. Moreover, the trend of potential real GDP growth in Euro area as estimated by the ECB staff is around 2-2.5\% p.a. Therefore, given the definition of price stability that the Harmonised Index of Consumer Price (HICP) inflation in Euro area must be below $2 \%$, the $\mathrm{ECB}$ can derive the reference value of $\mathrm{M} 3$ growth by taking $d V / d t=0.5-1 \%$ p.a., $d Q / d t=2 \%$ p.a., and $d P / d t<2 \%$ p.a.. Using the quantity equation, the resulting approximate level of the reference value of $\mathrm{M} 3$ is $d M / d t=4.5 \%$. Having derived the reference value of $\mathrm{M} 3$ growth of $4.5 \%$, the monetary policy analysis in the first pillar is directed towards assessing the risks to price stability as a result of the deviations of the actual M3 growth from the publicly announced reference value of $\mathrm{M} 3$ growth (the monetary disequilibria). To do this, the ECB staff develops several measures of monetary disequilibria and explain the prospect of inflation using such measures.

Assuming that monetary policy formulation is conducted only within the first pillar, then the policy response of the ECB will be to increase the interest rate if it observes a sustained increase in monetary disequilibria, and vice versa. However, this response will not be mechanistic in nature such as using a strict monetary policy rule linking the deviations of M3 growth from the reference value with the short term interest rate as the monetary policy instrument. Instead the ECB staff will analyse the sources of such sustained deviations of the actual M3 growth from its reference value. This analysis will include separating the specific factors affecting the demand for money and the factors constituting risks to price stability. Within the specific factors we may have factors such as institutional changes in banking sectors, financial innovations, changes in taxes, changes in reserves requirement, and changes 
in the use of currencies in other countries. All of these specific factors, by definition, do not impose risks to price stability, therefore any deviations of the actual M3 growth coming from these specific factors will not lead to a shift in the policy stance of the ECB. Otherwise, the ECB staff will propose a change in the interest rate stance, but this is only recommended after a cross checking is conducted to see if the risks to price stability are also signalled by the analysis in the second pillar.

Looking at the above one may observe the similarity between the ECB's first pillar strategy with the old-tradition of monetary targeting as proposed by the monetarist school of thought ${ }^{48}$. Both view inflation as the ultimate objective of monetary policy and money serves as a crucial variable in determining inflation over the long run. Moreover, both also see the merit of controlling the growth of monetary aggregate to provide operational framework for monetary policy. Furthermore, in both ECB first pillar and monetary targeting framework, the acknowledgement of the lags in the effect of monetary policy lead to the view that money is a leading indicator of inflation and therefore policy responds should be conducted in a preemptive manner by controlling the current excess growth of nominal money.

However, there are several features that distinguish the ECB first pillar with the monetary targeting framework. First of all, in the ECB first pillar strategy, the reference value of broad money (the M3 aggregate) is not used as the intermediate target of monetary policy. Instead it is only a tool (a thermometer one may say) to signal risks to price stability. In contrast, in the monetary targeting framework, broad money aggregate is treated as the intermediate target of monetary policy, and the central bank adopting this strategy is deliberately attempting to keep the fluctuations of this intermediate target close to its targeted level.

The second difference between the ECB first pillar strategy and the monetary targeting framework can be found in the way monetary policy is being conducted. Within the ECB first pillarstrategy, the stance of the interest rate policy is formulated after examining the results of analysis done in both the first and second pillar. In monetary targeting framework, at least in its purest theoretical form, monetary policy is formulated mainly using a passive policy rule. For instance, money supply is restricted to grow only at a constant and small rate in accordance to the forward looking estimate of the real need of the economy [The Friedman's passive $\mathrm{k} \%$ constant money growth rate rule].

Meanwhile, the second pillar of the ECB strategy is the use of a broad based assessment on the outlook of price development. This assessment is intended to complement the analysis conducted within the first pillar. In other words as illustrated in Diagram 1, the ECB staff will cross check the analytical results in the first pillar with those in the second pillar. The main difference between the first and the second pillar is in the treatment of money. While money is

48 For a review on the monetary targeting framework see Bryant (1980, p 69-82) 
the main component used in the analysis within the first pillar, the second pillar leaves money out of the picture. The ECB will look at other variables other than money and extract the signals of risks to price stability. Accordingly, the two pillars complement each other and reflect the existing division in the understanding of the nature of inflation process both in the academic and practical fields.

To extract signals of risks to price stability in the second pillar, the ECB staff will assess future inflation in the Euro area using all the ex-antenon-monetary information available and incorporate them into non-monetary empirical models of inflation. As described in the "Guide to Euro-system Staff Macroeconomic Projection Exercises" [ECB, June, 2001], the Euro-system macroeconomic projection is a combination of cyclical analysis, econometric model projections, and judgemental assessments on the basis of expert knowledge. For the cyclical analysis, the ECB has developed the coincident and leading indicators of economic growth and inflation. For the econometric projections, the ECB staff combines several tools of projection including the Vector Autoregressive (VAR) models, the Bayesian VAR models, the ARIMA time series models, the structural Phillips Curve equations, the reduced form equation systems, and the small as well as large scale macro-econometrics model. Using all these tools the ECB staff prepares report on the conditional economic forecasts and the risks to price stability in the Euro area. The report consists of the results from several projection exercises given the underlying assumptions with regards to the exogenous variables applicable to the Euro area. These exogenous variables are: the interest rates, the exchange rates, the international environment, and the fiscal variables. The Working Group on Forecasting (WGF) reporting to the Monetary Policy Committee (MPC) is responsible for the projections made by the ECB. This group is a group of macroeconomic and econometric experts affiliated with the ECB and the National Central Banks (NCB) that are the members of the European System of Central Bank (ESCB). The final macroeconomic projections for the Euro area made by WGF is called the aggregation of the agreed revised country projections. Based upon the agreed revised country projections which serve as the output of the second pillar analysis, a cross checking is done to see if the results in the first pillar are in conformity.

If the ECB Governing Council relies solely upon the second pillar in judging the stance of monetary policy in Euro area, then the open market operation will be conducted to increase the very short-term interest rate on liquidity in the financial market if the revised country inflation projections and other non monetary indicators signal risks to price stability. A student in monetary strategy will be quick to point out that this type of strategy looks very similar to that employed by countries adopting the direct inflation targeting framework such as the UK, Canada, Australia, New Zealand, and Chile ${ }^{49}$. That is a reliance on the use of a conditional inflation forecast based on the development in non-monetary indicators as the

49 For a review on the inflation targeting framework, see Bernanke, et. al. (1999) 
intermediate target of monetary policy. However, the ECB second pillar, does not regard the conditional inflation forecast as an intermediate target of monetary policy. It merely recognizes it as a tool (again, a thermometer) that signals the risks to price stability. Corollary to this is the second difference between the ECB second pillar strategy and the direct inflation-targeting framework. The direct inflation targeting framework argues for the employment of a "constrained discretionary policy rule" in guiding the central bank's interest rate decisions. This amounts to linking the conditional inflation forecast or the intermediate target of policy to the very short-term interest rate or the policy instrument using a policy feed back mechanism. If the conditional inflation forecast deviates from the inflation target then the interest rate will be adjusted according to the parameters of the forward looking policy feed-back rule plus some allowance for policy discretions. In contrast, the ECB second pillar dictates that the formulations on policy stance must be done only after a cross check with the first pillar is conducted.

From the above discussions, it is clear that the ECB transparently uses a full information strategy in formulating its monetary policy decisions. In particular it uses all the relevant economic theories of inflation and all the available economic indicators for constructing risks to price stability. Is this type of full information strategy feasible in Indonesia?

We would argue that the adoption of the transparent full information strategy similar to the ECB strategy outlined above could also be implemented in Indonesia. This is because to date BI has completed several research programs aiming at the full-fledged implementation of the direct inflation targeting strategy, which could be seen as the second pillar component of the ECB type strategy. One instance of the preparation is documented in Alamsyah, et.al. (2001) who pointed out that: "within Bank Indonesia a number of studies have been conducted on the inflation cycle, the diffusion index of CPI, the leading indicators of inflation, and other leading indicators that help determine the direction of inflation; partial and general equilibrium models have also been built to forecast the inflation rate...(and) in general, this research indicates that theinflation rate in Indonesia is broadly predictable on the basis of variables that include theoutput gap, aggregate demand, real money balance, import prices, and theexchange rate". Another instance is documented in the work of Hutabarat et,al. (2000). In it the authors search the possibility of constructing a forward looking policy feed-back rule linking the SBI rate with the deviations of a conditional inflation forecast from the inflation target. The conditional forecast of inflation is constructed using the stable price New Keynesian model of inflation with output gap-inflation nexus serves as the centre of monetary policy transmission. Accordingly, this quantitative inflation model omits altogether the plausible presence of money-inflation nexus in Indonesia from the analysis. Since their work was done in the context of the preparations for adopting the inflation targeting regime in post crisis Indonesia, then it clearly reflects the same type of analysis as conducted within the second pillar of the ECB type strategy. 
The direct inflation-targeting framework itself is a form of commitment technology that has served its purpose well in most developed nations and some developing countries ${ }^{50}$. The strength of this regime is that it constrains monetary authority to stick to its low inflationtarget and forces it to assess in a forward looking manner the expected long run performance of the current policy decisions by looking at the future deviations of inflation forecast from the inflation target. Hence, monetary policy is geared towards a pre-emptive attack on future inflationary pressures. This type of decision process relates quite well with private agents' own rationality and forward-looking behaviours, since they too are assumed to optimise on their decisions rationally by performing similar conditional forecasts of inflation and takes into account BI's optimal policy decisions.

With the adoption of the forward looking decision rule such as in the direct inflation targeting framework, private agents will perceive that the central bank also "speaks" their language. This sense of similarity will make agents more comfortable in setting their inflation expectations according to the central bank pre-announced inflation objective. But this is true only on one condition, namely BI's conditional inflation forecast must conform the reality of the inflation process in Indonesia. In this sense, a strong focus on variables other than money in conducting the inflation forecast and formulating monetary policy such as done within the inflation targeting regime could be fatal in the long run in Indonesia. This is because as we have argued, money could also matter in explaining inflation in Indonesia, and hence the exclusion of money from the central bank's information set will constitute a loss of major information in explaining the inflation process in Indonesia. Assuming private agents in the financial market in Indonesia are using full information in constructing their conditional forecasts of inflation, in which there is no solid reason to assume otherwise, then the use of a less than full information criteria in BI's monetary policy formulation strategy will be perceived as a serious flaw in BI's reasoning on the nature of the inflation process in Indonesia. Since private agents' perceptions on the long run expected effectiveness of monetary policy is directly related to their formation of inflation expectations, and the expected inflations are the very channel in which BI must be relying upon, then the marginal treatment of money will undermine the efforts to achieve price stability in post crisis Indonesia.

An international observer has pointed out the merit of balancing BI's inflation assessment with a monetary analysis if BI is going to adopt the full-fledged inflation- targeting framework in the future. For instance John B. Taylor (2000) in his post-conference speech at BI stated that: "there are some good reasons to use a money baseinstrument in Indonesia .....as Ilook back at the last few years, it seems to me that there has been a quite significant correlation between money growth and inflation". He further asserted that Bank Indonesia should "go with the inflation

50 For instance in Chile since 1990 and Thailand since 1999. 
targeting approach and commitment to theflexibleexchangerate, but not to abandon the use of money as part of the process....I strongly recommend keeping the (demand for money equation) in your (econometric) model... and I don't see any reason not to set a money growth target consistent with inflation target...If there is a significant deviation from money growth target, it should be explained". These assertions seem to suggest the desirability of adopting the ECB-type full information strategy in post crisis Indonesia as opposed to the direct inflation targeting alone.

Therefore the types of monetary analysis of inflation such as prescribed by the first pillar of ECB strategy need to occupy a more strategic role in the future design of monetary policy framework in post crisis Indonesia. In part this has been shown by the adherence to the base money-targeting framework, which essentially uses a monetary analysis of inflation in formulating the base money target. Moreover, since the current base money targeting framework has shown signs of success in curbing inflationary pressures in post crisis Indonesia, then the adoption of monetary analysis of inflation such as done within the second pillar of the ECB strategy may also be feasible in Indonesia.

The feasibility of treating money as a tool to signal risks to price stability is further signified by the empirical discussions in section II and III above. We have argued that (1) the real demand for M1 is stable, (2) inflation is not a weakly exogenous variable in the M1 demand system, (3) the real domestic consumption is a weakly exogeneous variable, (4) inflation is determined by M1 disequilibria, (5) the cash component of M1 and base money is a long, strong, and robust leading indicator of inflation, and (6) it is possible into certain extent to have some control over cash in circulation and M1 by affecting agents' opportunity cost to hold excess cash, i.e. via SBI rate policy. Point (1) to (5) suggests that inflation could be the results of continuous presence of narrow money disequilibria, especially cash and M1 disequilibria. Point (5) and (6) imply BI could use the annual growth of cash or M1 disequilibria as a tool to signal risks to price stability and have some control over the disequilibria. For an illustration we provide some detail below on the feasibility of using cash disequilibria as a tool to signal risks to price stability in post crisis Indonesia.

Graph 7a and 7b depict the relationship between cash disequilibria and CPI inflation since 1980. The boxes represent the episodes from peaks to troughs in CPI inflation (the downturn phases of CPI inflation). The circle dots mark the turning points of CPI inflation and the diamond dots mark the turning points of the annual growth of cash disequilibria. Arrows pointing right signify lead relationships and an arrow pointing left signifies lag relationship. We learn from the two graphs that cash disequilibria is a long, strong, and robust leading indicator of CPI inflation resembling the relationship between the annual growth of nominal cash and CPI inflation as depicted in graph 1a and 1b. Clearly, the turning points of cash disequilibria consistently lead the turning points of CPI inflation after 
Graph 7a. The Relationship Between Cash Disequilibria and CPI Inflation (Pre-Crisis)

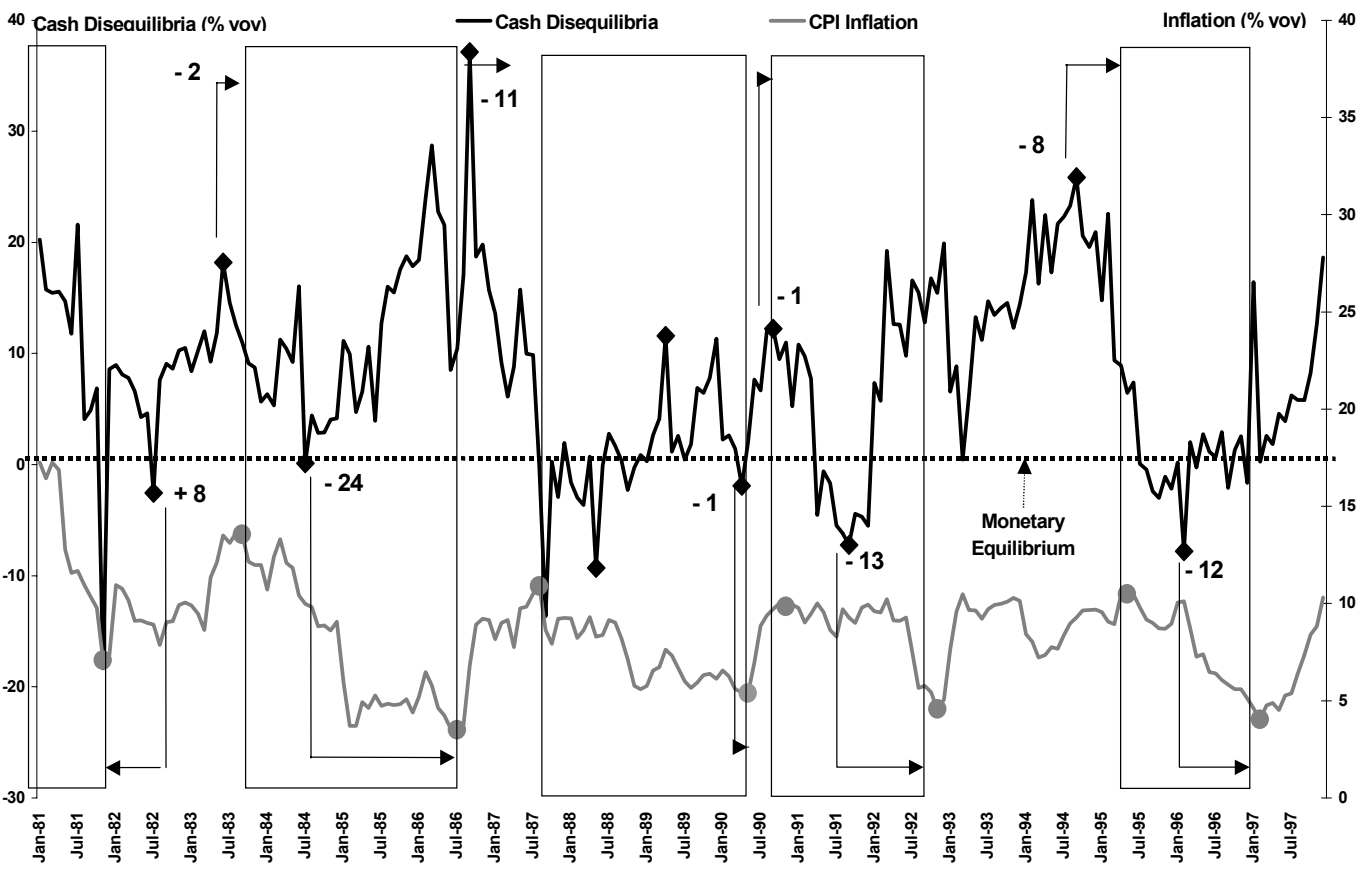

Graph 7b. The Relationship Between Cash Disequilibria and CPI Inflation (Crisis and Post Crisis)

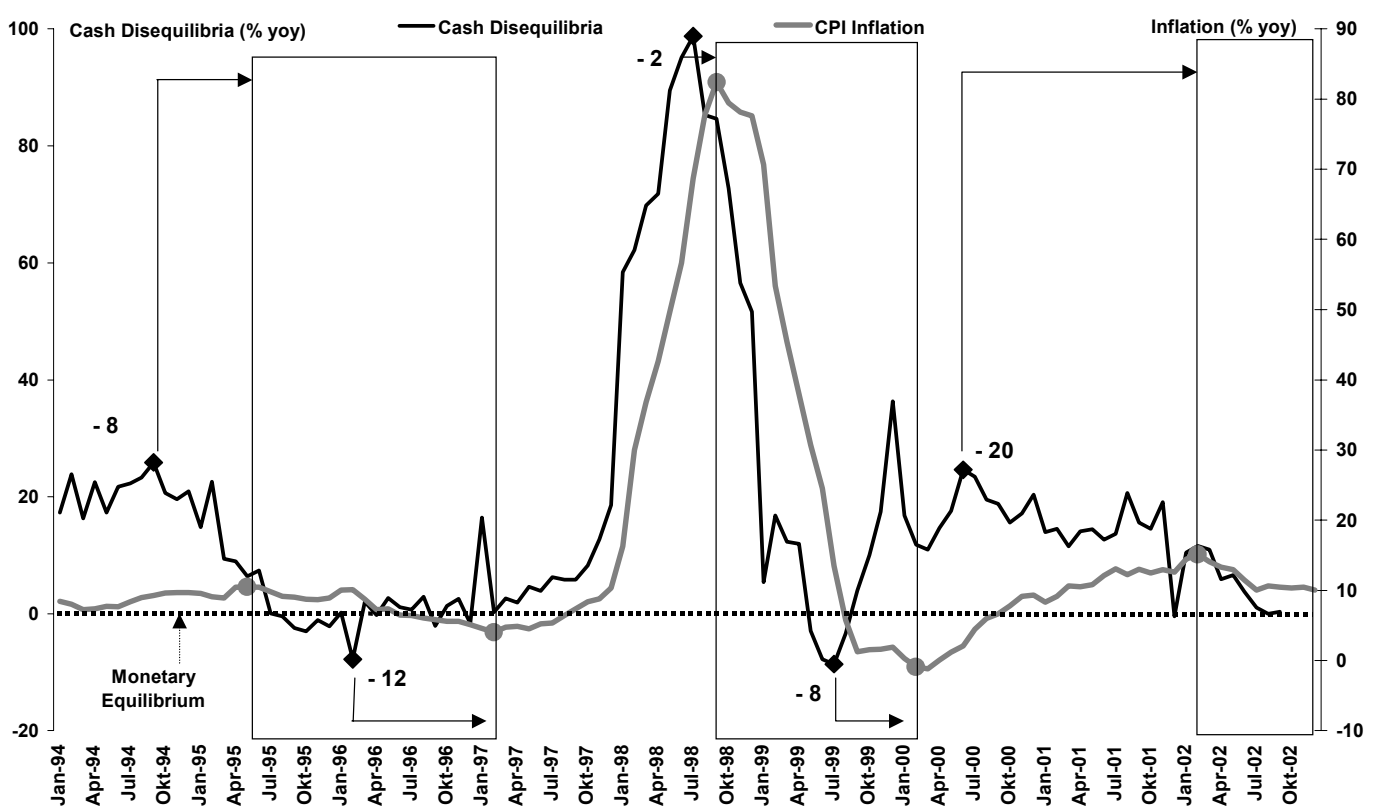


the interest rate deregulation in June 1983. This suggests that after some lags, the trend increase and decrease in cash disequilibria support the trend increase and decrease in CPI inflation in all episodes since the interest rate liberalization. It is also observable that whenever the annual growth of cash disequilibria falls within or below the monetary equilibrium line, after some lags we will see a corresponding trough in inflation. Similarly, whenever the annual growth of cash disequilibria goes above the monetary equilibrium line, we will observe an increase in inflation towards its peak ${ }^{51}$.

Furthermore, after the lag effects (pipeline effects) have been completed, cash disequilibria affect inflation in a one on one fashion. This conclusion is derived from the calculation reported in table 4 below. In the table we report the averages of the annual changes in cash disequilibria and CPI inflation over the cycles from peaks to peaks and troughs to troughs ${ }^{52}$. There are in total 11 episodes of such cycles. The differences are reported as the deviations between average values of the two series over the cycles. We also report the lengths of the lead relationship from the cycles of cash disequilibria to the cycles of CPI inflation.

Table 4. The Cyclical Relationships Between The Annual Growth of Cash Disequilibria and CPI Inflation since 1980

\begin{tabular}{|c|c|c|c|c|c|c|c|c|c|}
\hline \multirow[t]{2}{*}{ Episode } & \multirow[t]{2}{*}{ Peak to Peak } & \multicolumn{2}{|c|}{ Cash Disequilibria } & \multicolumn{2}{|c|}{ CPI } & \multirow[t]{2}{*}{ Deviation } & \multicolumn{2}{|c|}{ Lag (in months) } & \multirow{2}{*}{\begin{tabular}{|l|} 
Mean \\
Lag
\end{tabular}} \\
\hline & & P1 & P2 & P1* & P2* & & P1-P1* & P2-P2* & \\
\hline 1 & 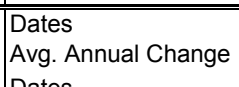 & $\begin{array}{|ll|}\text { Jun } 83 & \\
& 12.3 \\
\end{array}$ & Sep 86 & Aug 83 8.0 & Aug 87 & 4.3 & -2 & -11 & -6.5 \\
\hline 2 & $\begin{array}{l}\text { Dates } \\
\text { Avg. Annual Change }\end{array}$ & $\begin{array}{ll}\text { Sep } 86 & \\
& 4.9\end{array}$ & Sep 90 & Aug 87 & Oct 90 & -2.7 & -11 & -1 & -6 \\
\hline 3 & $\begin{array}{l}\text { Dates } \\
\text { Avg. Annual Change }\end{array}$ & $\begin{array}{|ll|}\text { Sep } 90 & \\
& 10.4\end{array}$ & Sep 94 & 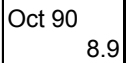 & May 95 & 1.5 & -1 & -8 & -4.5 \\
\hline 4 & $\begin{array}{l}\text { Dates } \\
\text { Avg. Annual Change }\end{array}$ & $\begin{array}{|ll|}\text { Sep } 94 & \\
& 16.63\end{array}$ & Jul 98 & $\begin{array}{c}\text { May } 95 \\
16.95\end{array}$ & Sep 98 & -0.32 & -8 & -2 & -5 \\
\hline 5 & $\begin{array}{l}\text { Dates } \\
\text { Avg. Annual Change }\end{array}$ & $\begin{array}{ll}\text { Jul } 98 & \\
& 26.56\end{array}$ & Jun 2000 & $\begin{array}{c}\text { Sep } 98 \\
19.86\end{array}$ & Feb 2002 & 6.7 & -2 & -8 & -5 \\
\hline \multirow[t]{2}{*}{ Episode } & Trough to Trough & \multicolumn{2}{|c|}{ Cash Disequilibria } & \multicolumn{2}{|c|}{ CPI } & Deviation & \multicolumn{2}{|c|}{ Lag (in months) } & \multirow{2}{*}{\begin{tabular}{|l|} 
Mean \\
Lag
\end{tabular}} \\
\hline & & \begin{tabular}{|l|} 
T1 \\
\end{tabular} & T2 & T1* & T2* & & & T2-T2* & \\
\hline 6 & $\begin{array}{l}\text { Dates } \\
\text { Avg. Annual Change }\end{array}$ & $\begin{array}{|ll|}\text { Jul } 82 & \\
& 9.35 \\
\end{array}$ & Jul 84 & $\begin{array}{r}\text { Nov } 81 \\
8.51\end{array}$ & Jul 86 & 0.84 & 8 & $\begin{array}{ll}-24 \\
\end{array}$ & -8 \\
\hline 7 & $\begin{array}{l}\text { Dates } \\
\text { Avg. Annual Change }\end{array}$ & Jul 84 & Apr 90 & \begin{tabular}{|r|} 
Jul 86 \\
\\
7.53
\end{tabular} & May 90 & -0.21 & -24 & -1 & -12.5 \\
\hline 8 & $\begin{array}{l}\text { Dates } \\
\text { Avg. Annual Change }\end{array}$ & 3.72 & Sep 91 & $\begin{array}{r}\text { May } 90 \\
8.65\end{array}$ & Nov 92 & -4.93 & -1 & -13 & -7 \\
\hline 9 & $\begin{array}{l}\text { Dates } \\
\text { Avg. Annual Change }\end{array}$ & 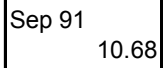 & Feb 96 & $\begin{array}{r}\text { Nov } 92 \\
8.35\end{array}$ & Feb 97 & 2.33 & -13 & -12 & -12.5 \\
\hline 10 & $\begin{array}{l}\text { Dates } \\
\text { Avg. Annual Change }\end{array}$ & $\begin{array}{|ll|}\mid \text { Feb } 96 & \\
& 24.09\end{array}$ & Jul 99 & $\left|\begin{array}{r}\text { Feb } 97 \\
28.48\end{array}\right|$ & Mar 2000 & -4.39 & -12 & -7 & -9.5 \\
\hline 11 & $\begin{array}{l}\text { Dates } \\
\text { Avg. Annual Change }\end{array}$ & 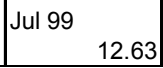 & End 2002 & $\begin{array}{r}\text { Mar } 2000 \\
9.2 \\
\end{array}$ & End 2002 & 3.43 & -8 & n.a. & -8 \\
\hline
\end{tabular}

51 Monetary equilibrium line is the line where the difference between the annual growth of nominal cash and the annual growth of real domestic households' consumption is equal zero. This line also signifies a position where the growth of nominal money equals the growth of the real demand for money.

52 One cycle is an episode from peak to peak or trough to trough. 
It can be learned from table 4 that there are deviations between the average values of cash disequilibria and the average values of CPI inflation over the cycles. Some are positive and some are negative. The deviations can be treated as the annual changes in the inverse velocity of cash in circulation because from the quantity theory we know that $\ddot{M}$ - ̈̈Q - ̈̈P $=-\ddot{A} \mathrm{~V}$. Such deviations are not zero in each the episodes, in which case suggests the presence of a constant inverse velocity overtime. However, the average of the inverse velocity overtime is zero. This implies that the inverse velocity of cash in circulation, although not constant, it is stable and mean reverting overtime. This is depicted in graph 8a. Putting the episodes in sequence since 1980 suggests that the long run expected value of the inverse velocity of cash is 0,6 and falls within predictable standard deviations. This result implies that in the long run inflation could be expected to move in a one-on-one fashion with the changes in annual growth of cash disequilibria.

Graph 8a. The Inverse Velocity of Cash in Circulation Over The Cycle

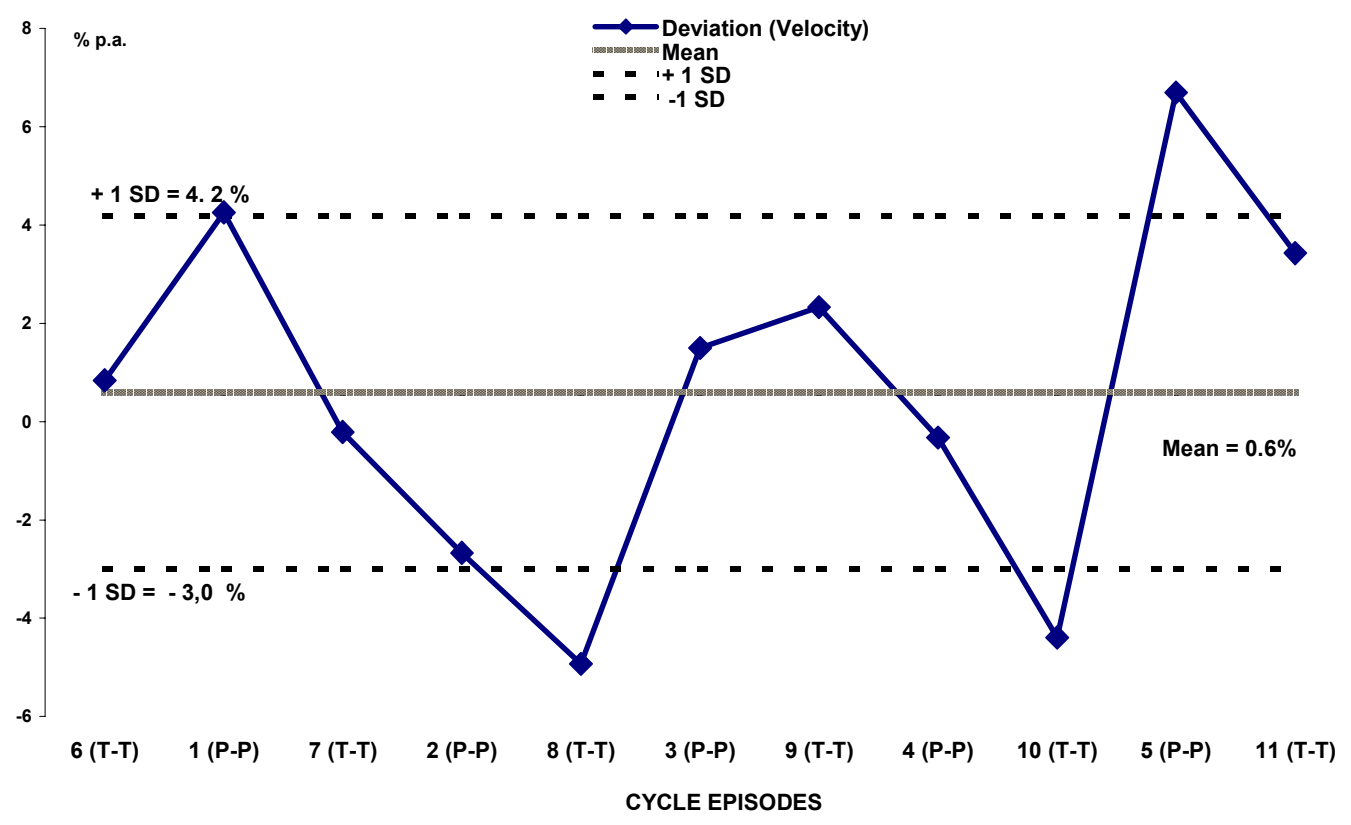

If we further compare the stability of the inverse velocity of cash in circulation with the inverse velocities of other monetary aggregates, we can see that only the inverse velocity of M1 that has the same persistent stability overtime. Using annual data series, we illustrate the comparison in graph $8 \mathrm{~b}$ and $8 \mathrm{c}$ below. In these two graphs, inverse velocity is defined as the $\Delta \mathrm{M}-\Delta \mathrm{C}-\Delta \mathrm{P}$, where : 


\section{Graph 8b. Inverse Velocities of Cash and M1}

(Annual Data)

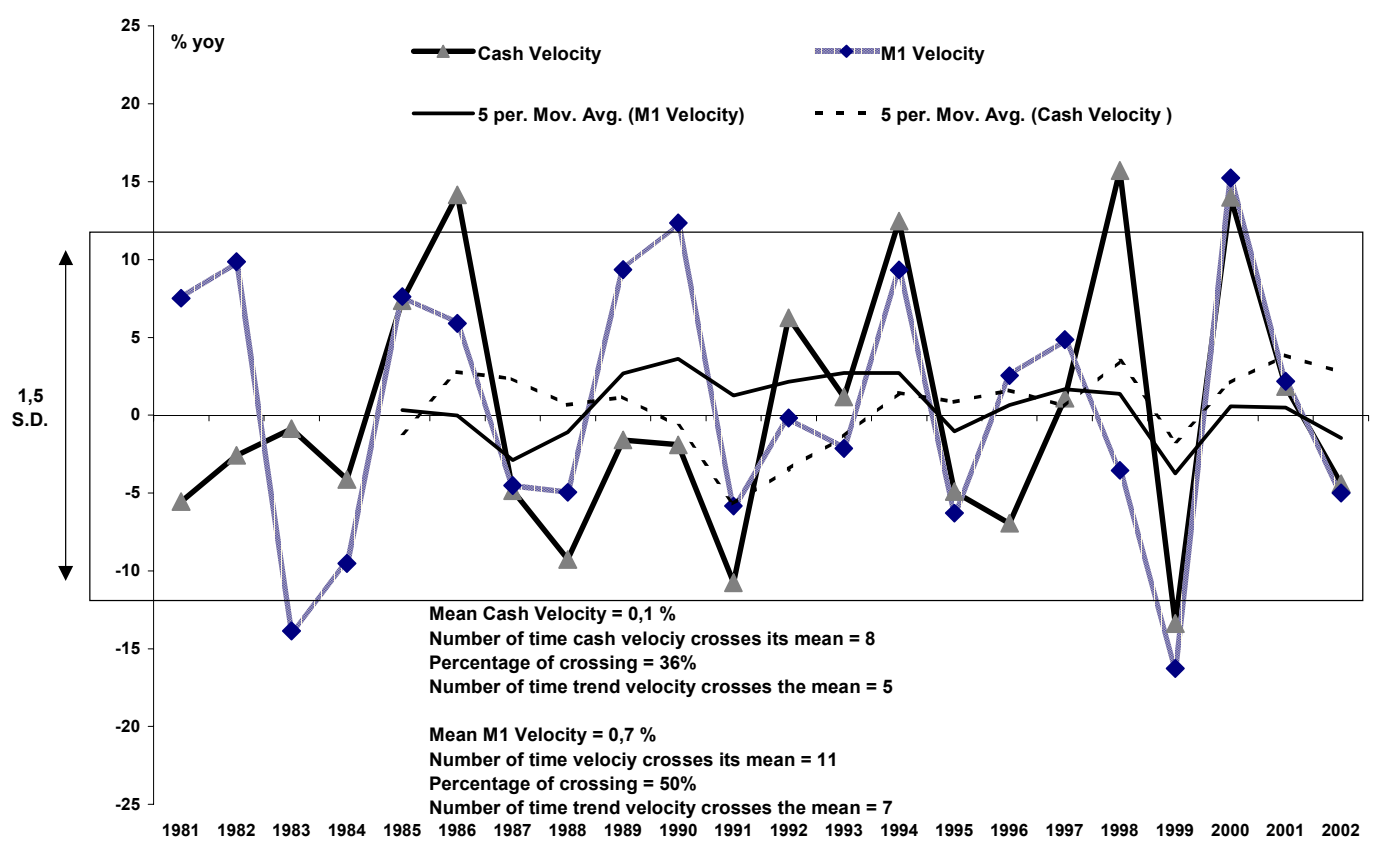

Mis the nominal monetary aggregate, $\mathrm{C}$ is the real domestic households' consumption, $\mathrm{P}$ is $\mathrm{CPI}$, and $\ddot{\mathrm{A}}$ is annual changes. It can be learned from the graphs that cash in circulation and $\mathrm{M} 1$ are the better indicators to predict inflation because their inverse velocities provide better signals of stability overtime to policy makers. For instance the trend inverse velocities of cash and M1 in circulation crosses its mean (equilibrium) more often than the inverse velocity of base money (BM) or M2. It can also be seen that the inverse velocity of M2 has a trend decline since 1990, while the inverse velocity of BM has a trend increase since 1990. Meanwhile, the velocities of both cash and M1 have stable trends overtime since 1980 . Hence the stability of the inverse velocities of cash and M1 are also robust across regime changes that have prevailed in Indonesia since 1980.

One additional observation that stands out from the relationship between cash disequilibria and CPI inflation is stability of the lead relationship from cash disequilibria to CPI inflation over the cycles. In other words, when one observes that the annual growth of cash disequilibria series has started / finished its complete cycle from peak to peak or trough to trough, then after some predictable lags one can observe the CPI inflation series starts / finishes its complete cycle. In graph 9 below we plot the average lead relationship from the annual growth of cash disequilibria to CPI inflation over the cycles in the sequence of 11 episodes as observed in table 4 above. As can be seen from the graph the lead relationship 
Graph 8b. Inverse Velocities of Base Money (BM) and M2

(Annual Data)

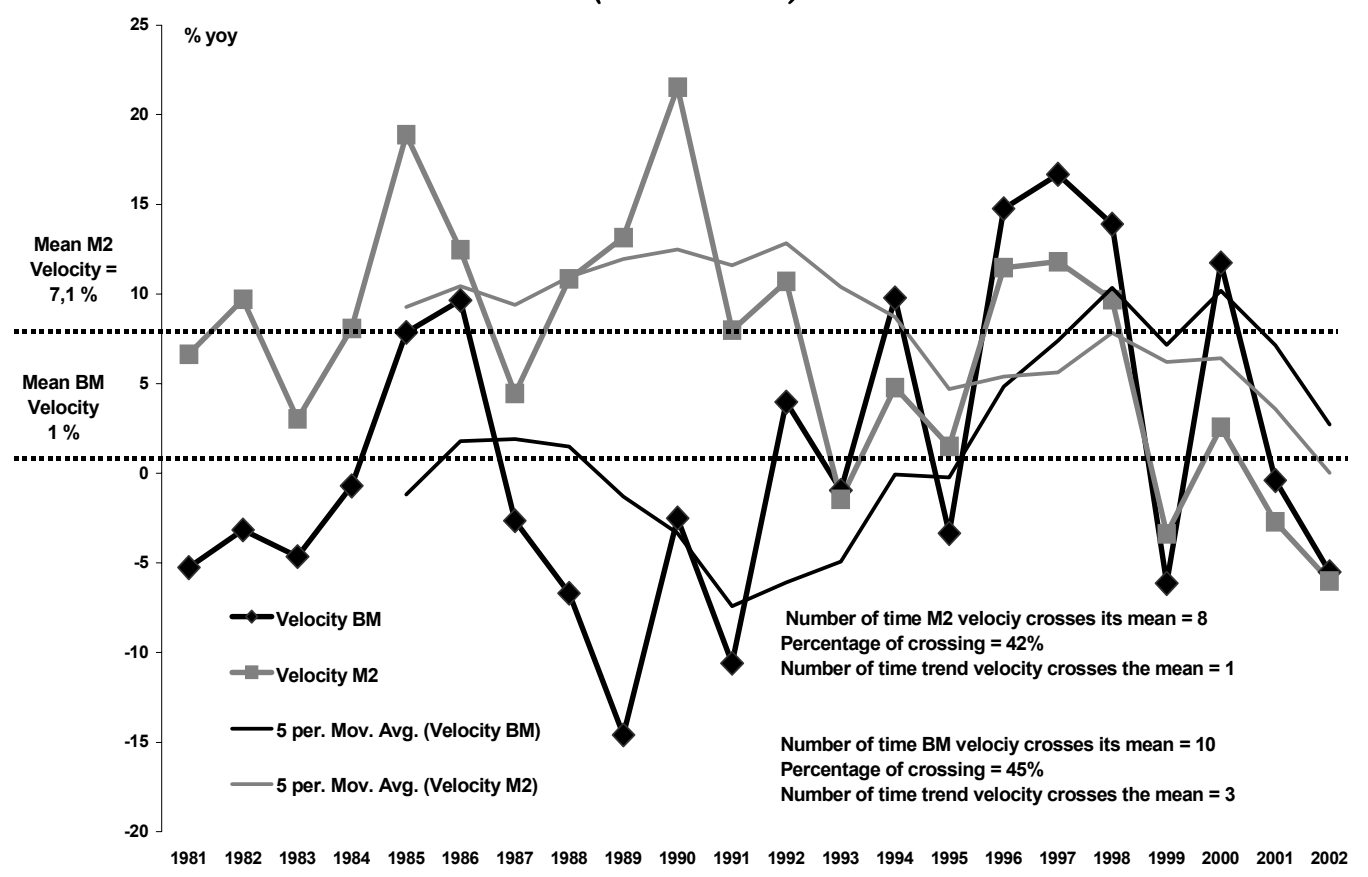

from the former to the later is on average 7,6 months over all the cycles. Taking into account the standard deviations, the lead relationship could run from 4,8 months to 10,4 months. Since we observe that this lead relationship holds and never fail despite the structural and regime changes that have happened in the economy since 1980, then such a relationship is robust.

Given the above and the fact that BI could have some influence over the opportunity cost of holding excess cash balance by manipulating its interest rate policy, then it is quite feasible to have a reference value of money growth in terms of either cash in circulation or M1 in post crisis Indonesia to signal risks to price stability. It is also feasible to have a reference value of money growth in terms of base money since its primary component is cash in circulation, however BI must carefully consider the probable sources of instability within the non-cash component of base money each time it formulates its monetary policy decisions ${ }^{53}$.

To sum up, BI should keep its current monetary analysis of inflation as embodied within the base money targeting framework. Especially when there are growing discourses within BI to implement the direct inflation targeting strategy as the future monetary policy framework in Indonesia. This is because as we have mentioned before, BI is playing against

53 For instance such instabilities could arise from the changes in reserves requirement, aggregate reserves deficiencies, and so on. 


\section{Graph 9. The Stability of The Lead Relationship From Cash Disequilibria to CPI Inflation Over the Cycles since 1980}

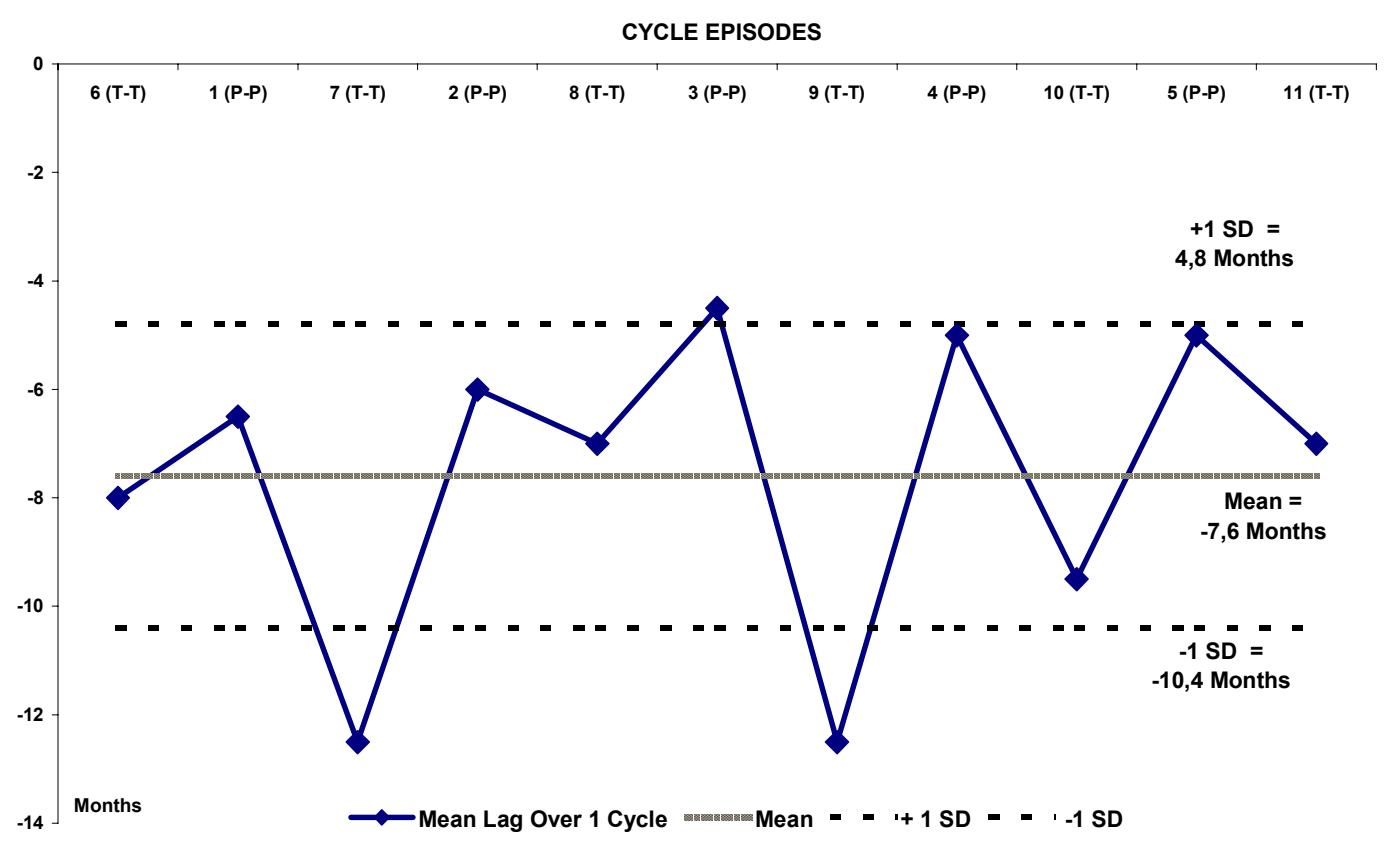

rational players in the market. Since rational players use a full information set in constructing their conditional inflation forecasts, then treating monetary analysis of inflation as sideline information will be a futile move for BI, especially when there are evidence that in the long run inflation could also be a monetary phenomenon in Indonesia. The danger will be amplified if the current base money-targeting framework continues to produce satisfactory results in keeping inflation low and stable in 2003. Such results will strengthen the notion that inflation is a monetary phenomenon in the long run in Indonesia. Hence there are merits in formally adopting the ECB type two pillars strategy in the future overall framework of monetary policy in post crisis Indonesia. Such a strategy avoids the marginal treatment of money and would assure sophisticated agents in the market that BI is also using full information criteria in formulating its monetary policy. This assurance could then induce agents to behave according to the policy stance and inflation target set by BI.

\section{CONCLUSIONS}

In this paper we have discussed the implementation of the base money targeting framework in Indonesia since 1999. It has been argued that the plausible existence of the monetarist type economic relations in Indonesia is one of the factor that has contributed to 
the initial success of the framework in stabilising the Rp/USD exchange rate and curbing the re-emergence of inflationary pressures in post crisis Indonesia. Other factor that has lent support is BI's overriding commitment to strictly adhere to the targeted monetary base. In the future, given the level of sophistication of agents in the financial market and into some extent in the goods market, it is preferable that BI uses a formal and transparent full information strategy in formulating its monetary policy in post crisis Indonesia. This amounts to adopting a monetary policy framework similar to the one used by the ECB.

\section{APPENDIX ${ }^{54}$}

\section{a. Background}

This appendix examines the stability of the demand for real narrow money and analyses the presence of the monetarist type economic relations in Indonesia ${ }^{55}$. We use a system estimation without prior assumptions made about the exogeneity / endogeneity status of the conditioning variables in the system. This way we will be able to test whether inflation in Indonesia is an endogenous phenomenon determined by excess money supply (monetary disequilibria) without imposing any theoretical priors. The methodology that we are using is the Johansen cointegrated vector autoregression (VAR) and its accompanying vector error correction modelling (VECM). Readers may consult Boswijk (1992), Franses (1998), Favero (2001), and Juselius (2002) for theoretical details on these methodologies. Applications similar to the one conducted in this section are available in Beyer (1998) and Juselius-Toro (1999).

\section{b. The Data}

With the exception of the quarterly real private domestic consumption spending, we use monthly data that are averaged to obtain the quarterly figures from Q1/1980 until Q4/ 2001. All the data are further transformed into logarithmic form except for the 1 month SBI rate. The notations used to identify the variables are as follows:

\footnotetext{
54 Due to limited space fuller results of the study can be requested directly from the author.

55 Previous studies have been conducted specific to the issue of money demand in Indonesia, i.e. Price and Insukindro (1994), Iljas (1998), Doriyanto (1999), Dekle and Pradhan (1999) and more recently in the IMF country report for Indonesia (IMF, Country Report 02/154, 2002). Meanwhile studies on the monetarist type inflation process have also been done, for instance in Sundrum (1973a, 1973b), Aghevli and Khan (1977), and McLeod (1997).
} 
$\mathrm{p}=$ the price level measured by $\log \mathrm{CPI}$,

$\mathrm{y}=$ the log real households' consumption expenditures,

$\mathrm{m}$ = the log nominal narrow money measured by M1 (currency in circulation plus the non-interest bearing demand deposits at commercial banks),

$\mathrm{R}=$ the 1 month nominal interest rate on Bank Indonesia Certificate (annualised, $\left.\times 10^{-2}\right)^{56}$.

$\Delta 4 \mathrm{p}=$ the CPI inflation (log year-on-year),

$\Delta 4 \mathrm{y}=$ the real households' consumption growth (log year-on-year),

$\Delta 4 \mathrm{~m}=$ the nominal M1 growth (log year-on-year),

Graph $1 a$ and $1 b$ plot the time evolution of the level and year on year changes of the data since Q1/1980. It is quite obvious from graph 1a that $y$ is clouded by strong seasonal components. Accordingly, on y we apply the standard seasonal decompositions using the census X-12 method without the trading day adjustments. Moreover, one can readily notice that the series in level possess strong trend components with significant breaks around late 1997. These breaks can be attributed to the monetary crisis that started in Q3/1997.

Graph 1.a Time Plots of the Series in Level
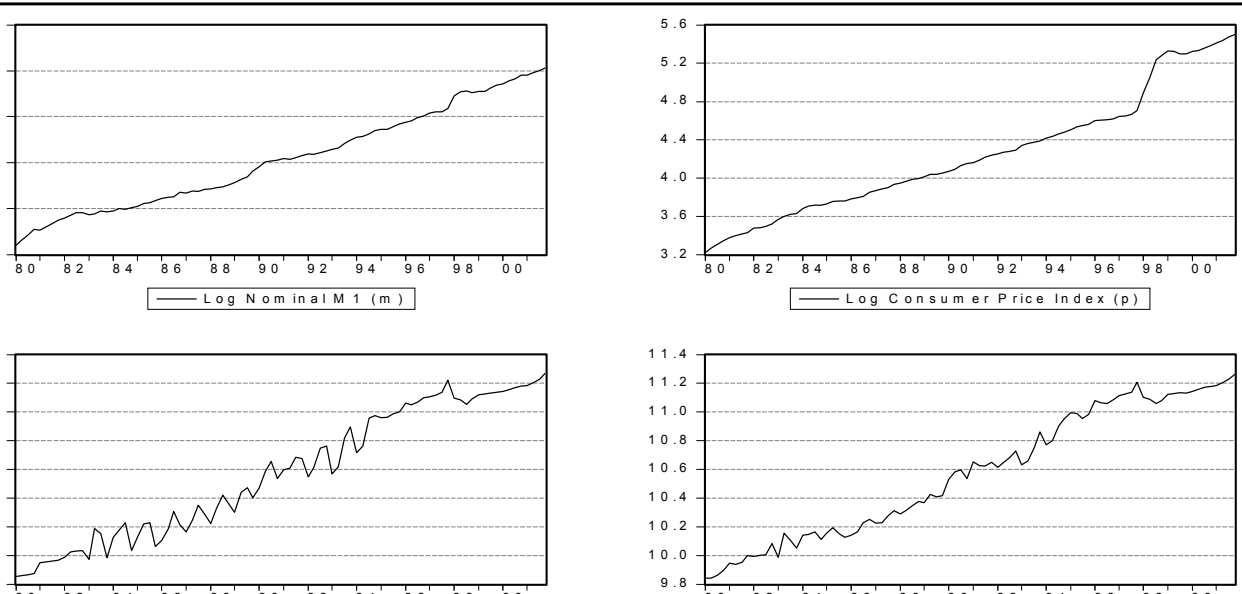

56 It must be noted that the data on R are not available for early 1980s and some periods in mid 1980s. As substitutes we use the mid-values of the highest and the lowest nominal 1-month time deposits at commercial banks (Data sources are Bank Indonesia's Annual Reports, 1980-1989). 
Graph 1.b. Time Plots of The Series in Annual Changes

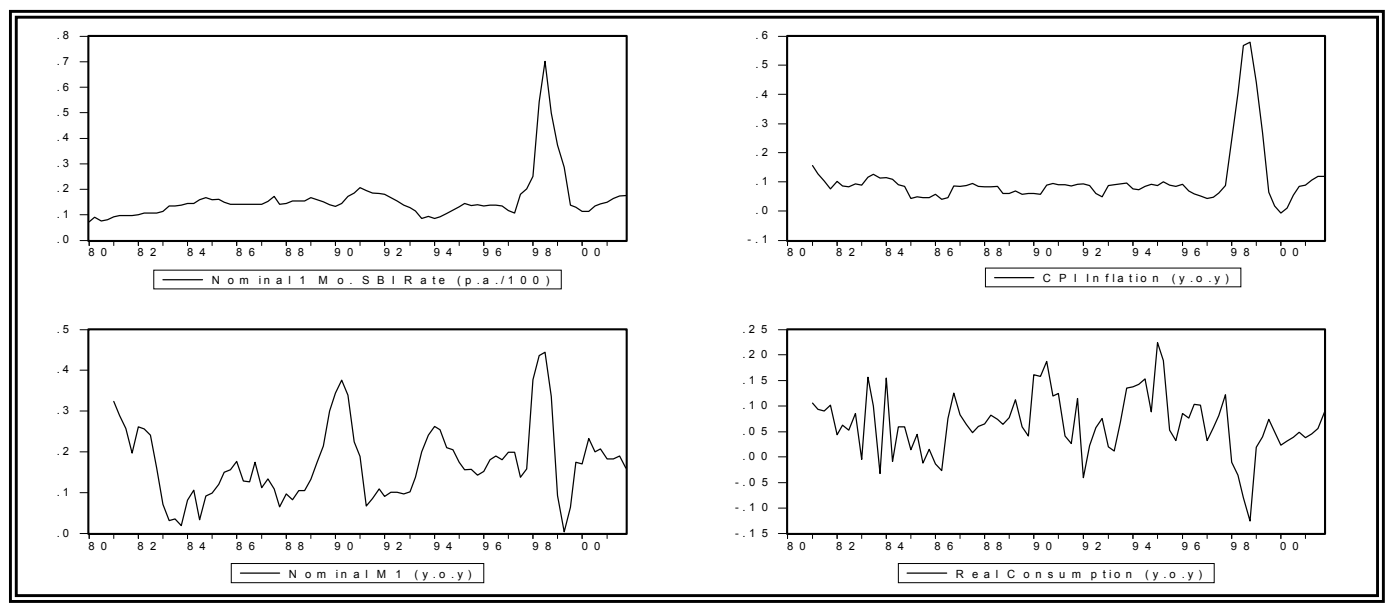

\section{The Long Run Analysis}

Our first aim is to empirically test for long run price homogeneity such that $p=1, m-p=0$. The second aim is to see the plausibility of the excess nominal monetary disequilibria having a feed back effect on the real growth of domestic households' consumption. The third aim is to examine the endogeneity/exogeneity status of price level in the system.

To accomplish the above we employ the VECM framework. We consider the following vector of variables $\boldsymbol{x}_{t}=[\boldsymbol{m} \boldsymbol{p} \quad \boldsymbol{y} \boldsymbol{R}]_{t}$ using $\operatorname{VAR}(4)$ to ensure that the serial correlations are amply removed and the multivariate normality is sufficiently established. We test for a cointegration in $\boldsymbol{x}_{\boldsymbol{t}}=\left[\begin{array}{llll}\boldsymbol{m} & \boldsymbol{p} & \boldsymbol{y} & \boldsymbol{R}\end{array}\right]_{\boldsymbol{t}}$ for the period Q1/1980-Q4/2001 using the Johansen test [Johansen (1988), (1995), Johansen - Juselius (1990)] allowing linear trends in the data and an intercept but no trend in the cointegrating equation. We obtain the results as reported in table 1 . Both the trace and the maximum eigen value statistics point to the existence of one cointegrating vector relating the elements of $x_{t}$.

In a VECM representation, the $\alpha \beta$ matrix is reported in table 2. Since $\beta_{\mathrm{p}}$ and $\beta_{\mathrm{y}}$ are approximately 1 we test for the individual and joint restrictions that $\beta_{\mathrm{p}}=\beta_{\mathrm{y}}=1$. Table 3 reports the results. We can accept that the restrictions apply individually and jointly. Therefore we impose the joint restrictions that $\beta_{\mathrm{p}}=\beta_{\mathrm{y}}=1$ in our cointegrating space. In addition, we test whether $\mathrm{m}$ is endogenous, and $\mathrm{p}, \mathrm{y}$ and $\mathrm{R}$ are exogenously determined within the system. Such a test amounts to testing for weak exogeneity in the conditioning variables in the sense of Engle, Hendry and Richard (1983) and Ericsson, Hendry, and Mizon (1998a), and illustrated in Johansen (1992b) and Boswijk (1992). Table 4 reports the results. The test 
results suggest that individually $\mathrm{m}, \mathrm{y}$, and $\mathrm{R}$ are weakly exogenous variables, while a joint test for $\alpha_{p}=\alpha_{y}=\alpha_{R}=0$ points to the acceptance of endogeneity in the conditioning variables. Since $p$ is the only variable that is endogenous individually, then the joint test is clouded by the endogeneity of $p$. Hence we can conclude that $p$ is long run homogenous and determined by $\mathrm{m}$ in a one-on-one fashion, and (2) $\mathrm{m}, \mathrm{y}$, and $\mathrm{R}$ are weakly exogenous variables.

Table 1. The Johansen Cointegration Test $x_{t}=[m \text { p y } R]_{t} ; Q 1 / 1980-Q 4 / 2001$

\begin{tabular}{|c|c|c|c|c|c|}
\hline & Eigen-value & $\begin{array}{c}\lambda \text { trace }= \\
-\mathrm{T} \ln \left[1-\lambda^{*}{ }_{\mathrm{r}+1}\right]\end{array}$ & $5 \%$ c.v. & $\begin{array}{c}\lambda \max = \\
-\mathrm{T} \ln \left[1-\lambda_{\mathrm{r}+1}^{*}\right]\end{array}$ & $5 \%$ c.v. \\
\hline$\lambda^{*}{ }_{0}$ & 0.36 & 58.31 & 47.21 & 37.50 & 27.07 \\
$\lambda^{*}{ }_{1}$ & 0.17 & 20.81 & 29.68 & 15.89 & 20.97 \\
$\lambda^{*}{ }_{2}$ & 0.05 & 4.91 & 15.41 & 4.65 & 14.07 \\
\hline & Rank & $\mathbf{1}$ & & $\mathbf{1}$ & \\
\hline
\end{tabular}

Critical values are from Osterwald-Lenum (1992)

Table 2. The Cointegrating Relation and the Adjustment Coefficients $x_{t}=[m \text { p y } R]_{t} ; Q 1 / 1980-Q 4 / 2001$

\begin{tabular}{|c|c|c|c|c|c|c|c|}
\hline \multirow{2}{*}{$\begin{aligned} \Delta \mathrm{x}_{\mathrm{t}} \\
\Delta m_{t}\end{aligned}$} & \multirow{2}{*}{$\begin{array}{c}\alpha \\
\text { [s.e./ t-stat] } \\
\alpha_{\mathrm{m}}=-0.14 \\
{[0.11 /-1.28]}\end{array}$} & \multicolumn{5}{|c|}{$\begin{array}{c}\boldsymbol{\beta}^{\prime} \\
{[\text { s.e. / t-stat] }}\end{array}$} & \multirow{2}{*}{$\frac{x_{t}}{m_{t-1}}$} \\
\hline & & $\beta_{\mathrm{m}}$ & $\beta_{p}$ & $\beta_{y}$ & $\beta_{\mathrm{R}}$ & C & \\
\hline$\Delta p_{t}$ & $\begin{array}{c}\alpha_{p}=0.16^{* * *} \\
{[0.05 / 2.86]}\end{array}$ & 1 & $\begin{array}{r}-0.95^{* * *} \\
{[0.04 /-19.9}\end{array}$ & $\begin{array}{l}-1.08^{* * *} \\
{[0.06 /-17 .}\end{array}$ & $\begin{array}{l}0.67^{* * *} \\
{[0.22 / 3 .}\end{array}$ & 5.33 & $p_{t-1}$ \\
\hline$\Delta y_{t}$ & $\begin{array}{c}\alpha_{y}=0.02 \\
{[0.11 / 0.22]}\end{array}$ & & & & & & $y_{t-1}$ \\
\hline$\Delta R_{t}$ & $\begin{array}{c}\alpha_{R}=0.02 \\
{[0.07 / 0.34]}\end{array}$ & & & & & & $R_{t-1}$ \\
\hline
\end{tabular}

$* * *, * *, *$ denotes $1 \%, 5 \%, 10 \%$ level of significance respectively using 2 -tail test.

$\wedge \wedge, \wedge$, denotes $5 \%, 10 \%$ level of significance using 1-tail t-test.

$\alpha=$ vector of loading / adjustment coefficients; $\beta=$ cointegrating vector

$\mathrm{C}=$ constant; $\Delta=1^{\text {st }}$ difference operator 
Table 3. The Test Results for Restrictions on $\beta_{p}=\beta_{y}=1$

\begin{tabular}{|c|c|c|c|}
\hline Restricted $\boldsymbol{\beta}$ & $\boldsymbol{\beta} \boldsymbol{p}_{\boldsymbol{t}}=\mathbf{1}$ & $\boldsymbol{\beta y _ { t } = 1}$ & $\begin{array}{c}\text { Joint } \boldsymbol{x}^{2}(\mathbf{2}) \\
\beta_{p}=\beta_{y}=1\end{array}$ \\
\hline$x^{2}(1)$ & $\mathbf{0 . 9 5 ^ { * }}$ & $1.82^{*}$ & $2.82^{*}$ \\
{$[p$-value] } & {$[0.32]$} & {$[0.17]$} & {$[0.24]$} \\
\hline
\end{tabular}

* denotes acceptance of restriction at .5\% level of significance.

Table 4. The Results of Weak Exogeneity Test $x_{t}=[m p \text { y } R]_{t} ; \beta_{m}=\beta_{p}=\beta_{y}=1$ Q1/1980-Q4/2001

\begin{tabular}{|c|c|c|c|c|c|}
\hline Restricted $\alpha$ & $m_{t}$ & $p_{t}$ & $y_{t}$ & $y_{t}$ & $\begin{array}{c}\text { Joint } x^{2}(4) \\
\alpha_{p}=\alpha_{y}=\alpha_{R}=0\end{array}$ \\
\hline $\begin{array}{c}x^{2}(1) \\
{[p \text {-value }]}\end{array}$ & $\begin{array}{c}3.59 \\
{[0.30]}\end{array}$ & $\begin{array}{c}14.65^{*} \\
{[0.00]}\end{array}$ & $\begin{array}{c}3.05 \\
{[0.38]}\end{array}$ & $\begin{array}{c}3.19 \\
{[0.36]}\end{array}$ & $\begin{array}{c}17.82^{*} \\
{[0.003]}\end{array}$ \\
\hline
\end{tabular}

* denotes acceptance of endogeneity at .5\% level of significance.

Our next attempt is to jointly estimate the long run demand for real M1 balance with the long run Fisher type relation and see whether this attempt is empirically feasible. Table 5 reports this joint estimation and table 6 gives the test results for weak exogeneity and binding restrictions to obtain the specification in table 5 . It turns out that this joint estimation is attainable. For further analysis we take the results in table 5 as our final long run specification.

Table 5. The Long Run Specification of The Demand for

Real M1 Money Jointly Estimated with the Fisher Relation

Imposed rank $=2, x_{t}^{*}=\left[(m-p) \Delta_{4} p \text { y } R\right]_{t} ; Q 2 / 1982-Q 4 / 2001$

\begin{tabular}{|c|c|c|c|c|c|c|c|c|}
\hline$\ddot{A} x_{t}$ & $\begin{array}{c}\mathrm{a}_{1} \mathrm{a} \\
\text { [s.e./ } \mathrm{t} \text {-stat] }\end{array}$ & $\begin{array}{c}\mathrm{a}_{2} \mathrm{a} \\
\text { [s.e./ } \mathrm{t} \text {-stat] }\end{array}$ & \multicolumn{5}{|c|}{$\begin{array}{c}\hat{a}^{\prime} \\
{[\text { s.e. / t-stat] }}\end{array}$} & $x_{t}$ \\
\hline$\ddot{A}(m-p)_{t}$ & $\begin{array}{c}\text { á } 1_{\mathrm{m}-\mathrm{p}}=-\mathbf{0 . 3 5} * * * \\
{[0.10 /-4.28]}\end{array}$ & á $2_{\mathrm{m}-\mathrm{p}}=\mathbf{0}$ & $\begin{array}{l}\mathrm{a} 1_{\mathrm{m}-\mathrm{p}} \\
\mathbf{1}\end{array}$ & $\begin{array}{cr}1_{\text {Aंtp }} & \hat{\mathrm{a}}] \\
\mathbf{0} & -1.0 \\
{[0.02 /-47}\end{array}$ & & $\begin{array}{c}\hat{\mathrm{a}} 1_{\mathrm{R}} \\
0.18^{\wedge} \\
{[0.16 / 1.10]}\end{array}$ & $\begin{array}{c}\mathrm{C} \\
5.15\end{array}$ & $(m-p)_{t-1}$ \\
\hline$\ddot{A}^{2} p_{t}$ & $\begin{array}{l}\mathrm{a}_{1} \ddot{A}^{2}=0.10 * \\
{[0.05 / 1.81]}\end{array}$ & á $2_{\ddot{A} 4 \mathrm{p}}^{2}=\mathbf{0}$ & $\hat{\mathrm{a}} 2_{\mathrm{m}-\mathrm{p}}$ & $\hat{\mathrm{a}} 2_{\ddot{A} 4 \mathrm{p}}$ & $\hat{a} 2_{y}$ & $\hat{a} 2_{R}$ & $\mathrm{C}$ & $\ddot{A}_{4} \mathbf{p}_{t-1}$ \\
\hline$\ddot{A} y_{t}$ & á $1_{y}=0$ & $\begin{array}{l}\text { á } 2 y=-0.34 * * \\
{[0.17 /-2.01]}\end{array}$ & $\mathbf{0}$ & -1 & 0 & 1 & -0.06 & $y_{t-1}$ \\
\hline$\ddot{A} R_{t}$ & á $1_{\mathrm{R}}=\mathbf{0}$ & $\begin{array}{c}\text { á } 2=-0.27 * * * \\
{[0.09 /-2.92]}\end{array}$ & & & & & & $\boldsymbol{R}_{t-1}$ \\
\hline
\end{tabular}

$L R-x^{2}(6)=8.05, p$-value $=0.23$

Akaike Information Criteria $=-14.64$

Schwarz Information Criteria $=-12.12$

***,,$* *$, denotes $1 \%, 5 \%, 10 \%$ level of significance respectively using 2-tail test.

$\mathrm{a}_{1} \alpha, \mathrm{a}_{2} \alpha=$ column vector 1,2 of loading matrix $\alpha$, respectively $\beta 1, \beta 2=$ row vector 1,2 of cointegrating matrix $\beta^{\prime}$, respectively

$\wedge \wedge, \wedge$, denotes $5 \%, 10 \%$ level of significance using 1-tail t-test. $\quad \begin{array}{ll}C & =\text { constant } \\ \Delta, \Delta^{2} & =1^{\text {st }} \text { and } 2^{\text {nd }} \text { difference operator, respectively }\end{array}$ 
Table 6. The Results of Weak Exogeneity Tests and Binding Restrictions

\begin{tabular}{|c|c|c|}
\hline Restrictions on matrix áâ' & $\begin{array}{c}\text { LR } \div^{2}(2) \\
\text { [p-value] }\end{array}$ & Remarks \\
\hline á $1_{\mathrm{m}-\mathrm{p}}=\mathbf{0}$ & $7.58[0.02]$ & Endogenous in C.E. 1 \\
\hline á $1_{\ddot{A}^{2} 4 \mathrm{p}}^{2}=\mathbf{0}$ & $5.86[0.05]$ & Endogenous in C.E. 1 \\
\hline á $1_{\mathbf{y}}=\mathbf{0}$ & $0.06[0.96]$ & Weakly Exogenous in C.E. 1 \\
\hline á $1_{\mathrm{R}}=\mathbf{0}$ & $1.74[0.41]$ & Weakly Exogenous in C.E. 1 \\
\hline á $2_{\mathrm{m}-\mathrm{p}}=\mathbf{0}$ & $0.96[0.61]$ & Weakly Exogenous in C.E. 2 \\
\hline á $2_{\ddot{A} 4 \mathrm{p}}^{2}=\mathbf{0}$ & $2.07[0.35]$ & Weakly Exogenous in C.E.2 \\
\hline á $2=\mathbf{y}$ & $3.42[0.18]$ & Weakly Exogenous in C.E. 2 \\
\hline á $2_{\mathrm{R}}=\mathbf{0}$ & $0.51[0.77]$ & Weakly Exogenous in C.E. 2 \\
\hline$\hat{a} 1_{y}=1$ & $1.79[0.4]$ & Restriction applies \\
\hline â $2_{\mathrm{R}}=1$ & $17.46[0.0001]$ & Restriction does not apply \\
\hline Joint $\div^{2}(8)$ & $21.01[0.007]$ & Restriction does not apply \\
\hline Joint $\div^{2}(6):$ á $2_{\mathrm{R}}, \mathrm{a}_{\mathrm{y}}$ ? 0 & $8.05[0.23]$ & $R$ and $y$ are endogenous in C.E. 2 \\
\hline
\end{tabular}

Given the above long run specifications, it is quite informative to see how the economic relationships work in Indonesia. First of all the excess nominal narrow money supply (M1 disequilibria) above its real need for households' consumption affect the acceleration of inflation positively and directly in the long run. Second, M1 disequilibria have no long run direct effect on the real growth of domestic households' consumption. Third, the long run behaviour of SBI rate is affected by the level of inflation which means even though the changes in M1 disequilibria have no direct effect on the SBI rate in the long run, yet they have an indirect effect via the increasing inflation expectations. Fourth, the shocks to SBI rate have negative effects on the real growth of domestic households' consumption. Thus M1 disequilibria are not perfectly neutral in the long run since its impact on inflation expectations will be a factor that presses the SBI rate upward and adversely affect real output growth. In sum, the existence of monetary disequilibria is debilitative to inflation, SBI rate, and the real output performance in the long run, but its absence is facilitative to all.

For an illustration, we depict the cointegrating relation representing the M1 disequilibria in graph 2. As can be seen from the plot, M1 disequilibria fluctuate around its equilibrium path overtime. Except for the periods in 1998 and 1999, the fluctuations of the disequilibria are more or less contained within the +/- 0.1 deviations from monetary equilibrium. It is important to further assess whether such deviations in 1998-1999 represent systematic breaks in the common trend of the underlying variables or not. Several approaches to further examine this issue have been put forward in the section II of the paper. Results from further studies may / may not alter the results already obtained so far in the sense that our conclusions on the weak exogeneity status of the conditioning variables in table 6 may / may not change. 
Graph 2.

The Cointegrating Graph of The Equilibrium Real M1Demand System

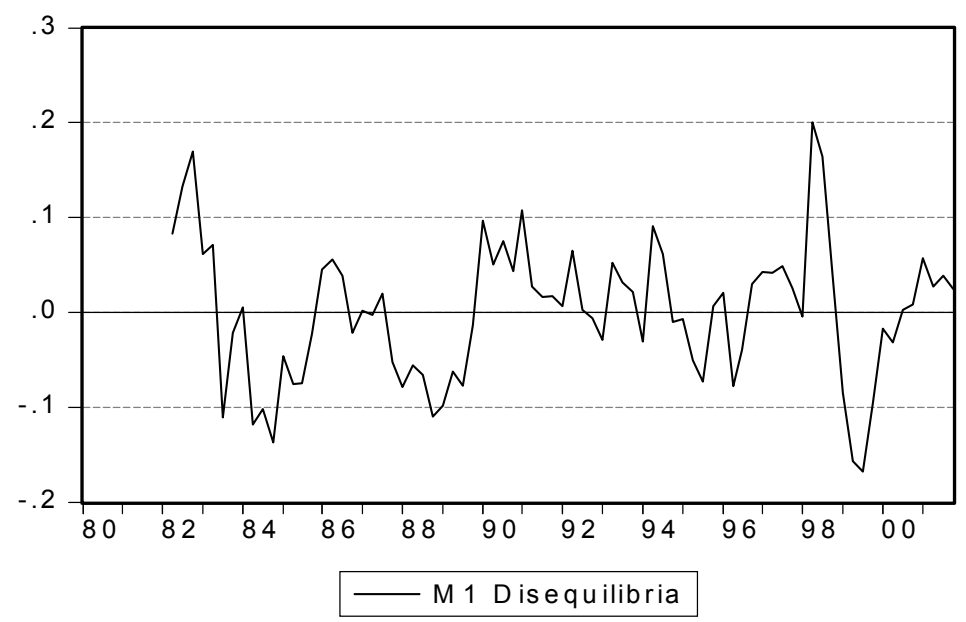

Therefore at this stage we can only safely conclude that inflation could be a monetary phenomenon in Indonesia since 1980, until more rigorous studies in line with HendryMizon (1998) and Johansen-Mosconi-Nielsen (2000) have been finalised.

\section{The EqCM Specification of the Demand for the Real M1 Balance}

Using the long run specification in table 5 we estimate the Equilibrium Correction Model $(E q C M)$ of the demand for real M1 in Indonesia. We employ the equilibrium correction model $(E q C M)$ as commonly referred and applied in the money demand literatures [see for instance Ericsson (1998), Hendry-Erricsson (1991), Beyer (1998)].

The general econometric specification of our model as derived from the VEC system in table 5 is as follows:

$$
\begin{aligned}
\ddot{\mathrm{A}}(\mathrm{m}-\mathrm{p})_{\mathrm{t}}= & \grave{\mathrm{i}}_{0}+\dot{\mathrm{O}}_{\mathrm{i}=1}^{4} \grave{\mathrm{e}}_{1} \ddot{\mathrm{A}}(\mathrm{m}-\mathrm{p})_{\mathrm{t}-\mathrm{i}}+\mathrm{O}_{\mathrm{i}=0}^{4} \grave{\mathrm{e}}_{2} \ddot{\mathrm{A}}(\mathrm{y})_{\mathrm{t}-\mathrm{i}} \\
& +\dot{\mathrm{O}}_{\mathrm{i}=0}^{4} \grave{\mathrm{e}}_{3} \ddot{\mathrm{A}}(\mathrm{R})_{\mathrm{t}-\mathrm{i}}+\dot{\mathrm{O}}_{\mathrm{i}-0}^{4} \grave{\mathrm{e}}_{4} \ddot{\mathrm{A}}(\ddot{\mathrm{A}} 4 \mathrm{p})_{\mathrm{t}-\mathrm{i}} \\
& +\dot{\mathrm{a}}_{1}\left[(\mathrm{~m}-\mathrm{p})-\hat{\mathrm{a}}_{11} \mathrm{y}+\hat{\mathrm{a}}_{12} \mathrm{R}+\mathrm{c}_{1}\right]_{\mathrm{t}-1} \\
& +\dot{\mathrm{a}}_{2}\left[\mathrm{R}-\ddot{\mathrm{A}} 4 \mathrm{p}+\mathrm{c}_{2}\right]_{\mathrm{t}-1}+\mathrm{a}_{\mathrm{t}}
\end{aligned}
$$

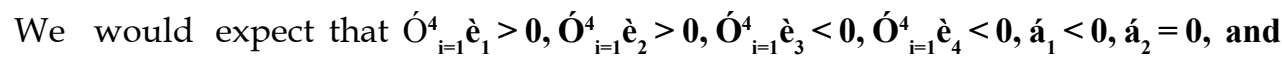
$\mathbf{a}_{\mathbf{t}} \sim$ NID $\left(\mathbf{i} \hat{\mathbf{o}}_{\mathbf{a}}^{2}\right)$. We obtain the general model and reduce it into the specific model and get the 
following preliminary EqCM specification in table 7, with long run stability of the equation plotted in Graph 3a and its fitted and residual values are plotted in Graph 3b.

Table 7. The Preliminary EqCM Specification

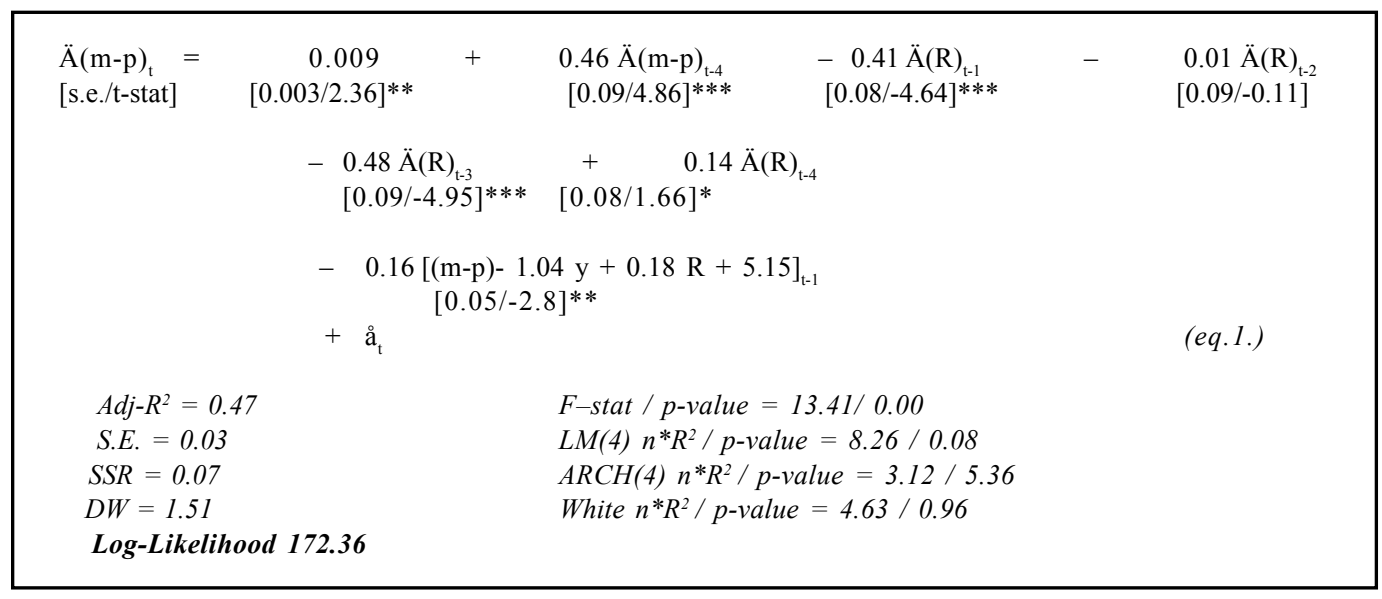

Graph 3a.

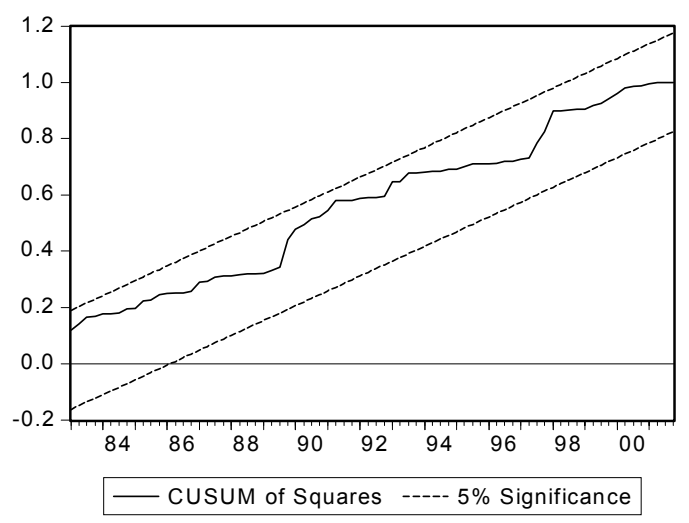

Graph 3b.

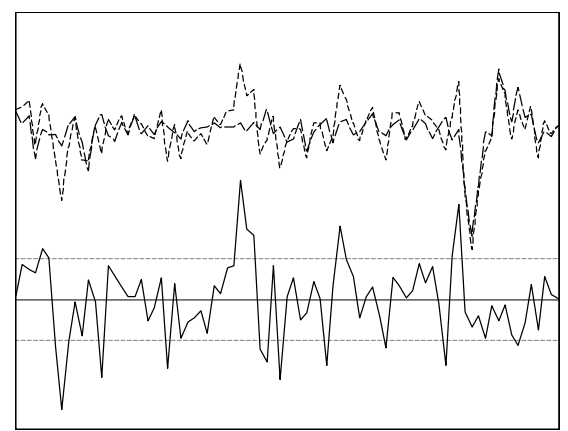

Three features stand out from the above preliminary specification. First of all, inflation failed to be a weakly exogenous factor that explains the real demand for M1. This result reasserts the result from the long run analysis that price is an endogenous variable in the long run money demand system. Accordingly, inflation is determined by the M1 disequilibria. Second, the demand for real M1 projects functional stability throughout the sample period despite the presence of structural breaks in its conditioning variables as suggested by the time series plots in graph $1 \mathrm{a}$ and $1 \mathrm{~b}$. Given this second feature we hypothesise that the wide swings of the M1 disequilibria during 1998-1999 in graph 2 do not represent non-systematic 
breaks among the conditioning variables in the VEC system. In other words, it could be the case that there is a common co-breaking vector that link all the variables in the vector $\mathrm{x}_{\mathrm{t}}^{*}=\left[(\mathrm{m}-\mathrm{p}) \ddot{\mathrm{A}}_{4} \mathrm{p} \text { y R }\right]_{\mathrm{t}}$ in the sense of Hendry-Mizon (1998), or the inclusion of a shift dummy as suggested by Johansen-Mosconi-Nielsen (2000) will not alter the already obtained results.

Third, we detect some evidence of serial correlations in the residuals that may cloud our judgement on the relative strength of the coefficients of $R$, the coefficients of interest for monetary policy makers. The presence of serial correlations is most apparent in late 1980s. Therefore we introduced the following pulse and shift dummies:

1. Level shifts in the nominal M1 in Q4/1989 and Q3/1993, and the joint pulse of the nominal M1, price, and real consumption in Q1/1998.

2. The level shifts in the nominal SBI rate in Q3/1990 and Q3/1997.

3. The level shift in real consumption in Q4/1993.

It must be noted that the inclusion of these dummies are done after we have established the functional stability of the demand for real M1 as suggested in graph 3a.

It is now a direct interest to see the stability of the parameters before the inclusion of these dummies. Graph 4 plots the recursive coefficients for each variable in eq. (1) in table 7. From graph 4 we notice that only the coefficients of $R$ that exhibit parameter non-constancy during the advent of the monetary crisis in 1997. The other parameters show constancy throughout the sample period despite the breaks. Thus, there is a major change in the process of $R$ as a conditioning variable. This is also reflected in the significance of the dummies for $R$ in eq. 2 in table 8. Since $R$ is BI's policy variable, then a test for super-exogeneity must be conducted before we can accept / reject the Lucas Critique ${ }^{57}$. Taking the fact that in the absence of a regime change the coefficients of $R$ are stable, then we take eq. 2 in table 8 as our final single equation EqCM for the demand for real M1 balance in Indonesia.

From table 8 we can see that the elasticity of the long run adjustment coefficient of real M1 balance is about $-0.17 \pm 0.05$. Meanwhile the lag real M1 balance adjusts in the short run with an elasticity of $0.41 \pm 0.08$ standard errors. For the nominal SBI rate, only two lags are significant, namely the lag 1 month and the lag 3 months. Nevertheless we keep the other lags to have a fuller picture of the strength of this policy variable. The sum of semi-elasticity coefficients of the SBI rate is about -0.69 . Thus in the short run, the SBI rate has a strong effect on M1 disequilibria. Taking into account the standard errors, the sum semi-elasticity coefficients could range from -0.42 to -0.82 .

57 As is suggested in Hendry-Ericsson (1991). This point constitutes a future extension for this study. 
Table 8. The Respecified EqCM Specification

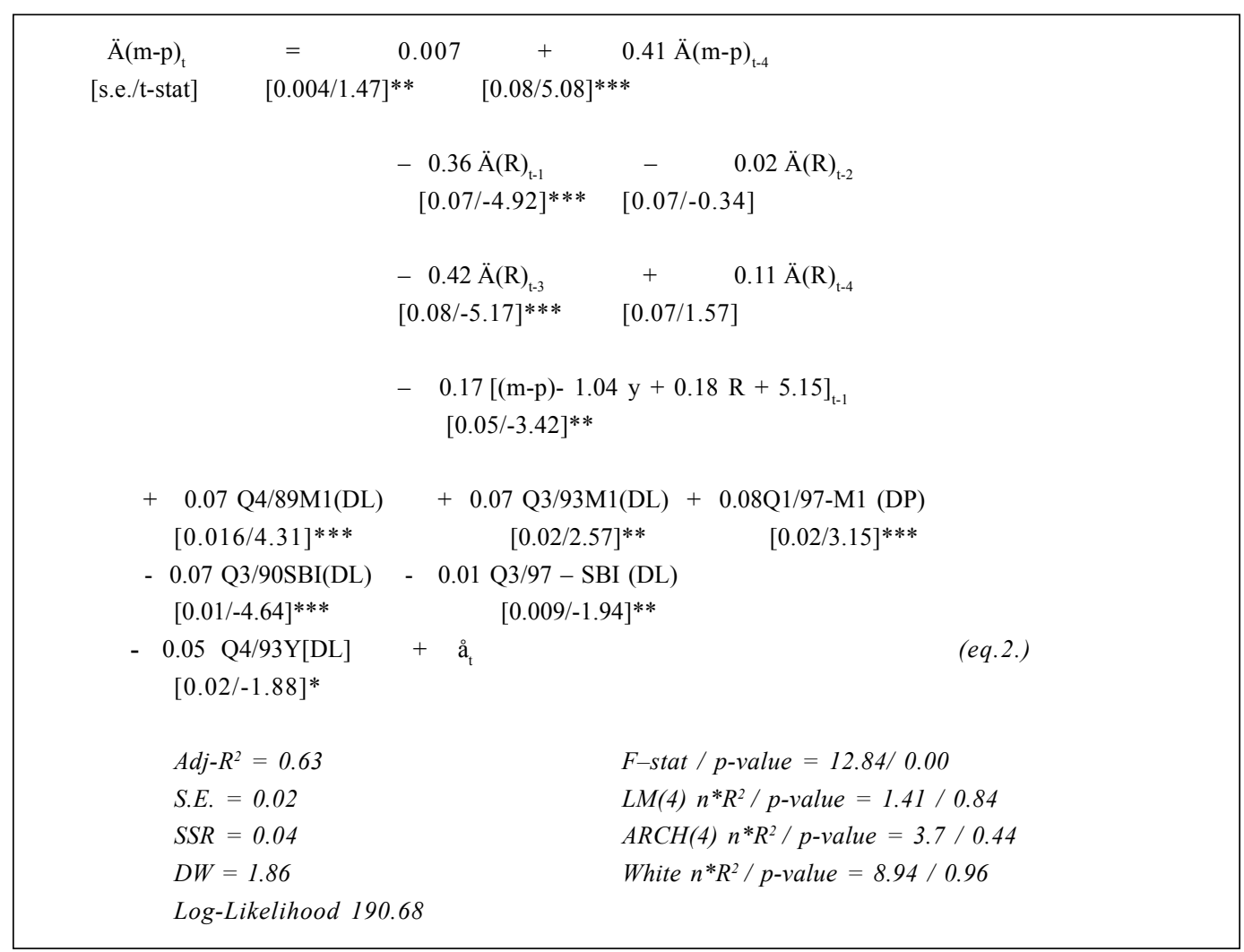




\section{Graph 4. Recursive Coefficients Full Sample}

Before The Inclusion of Dummies
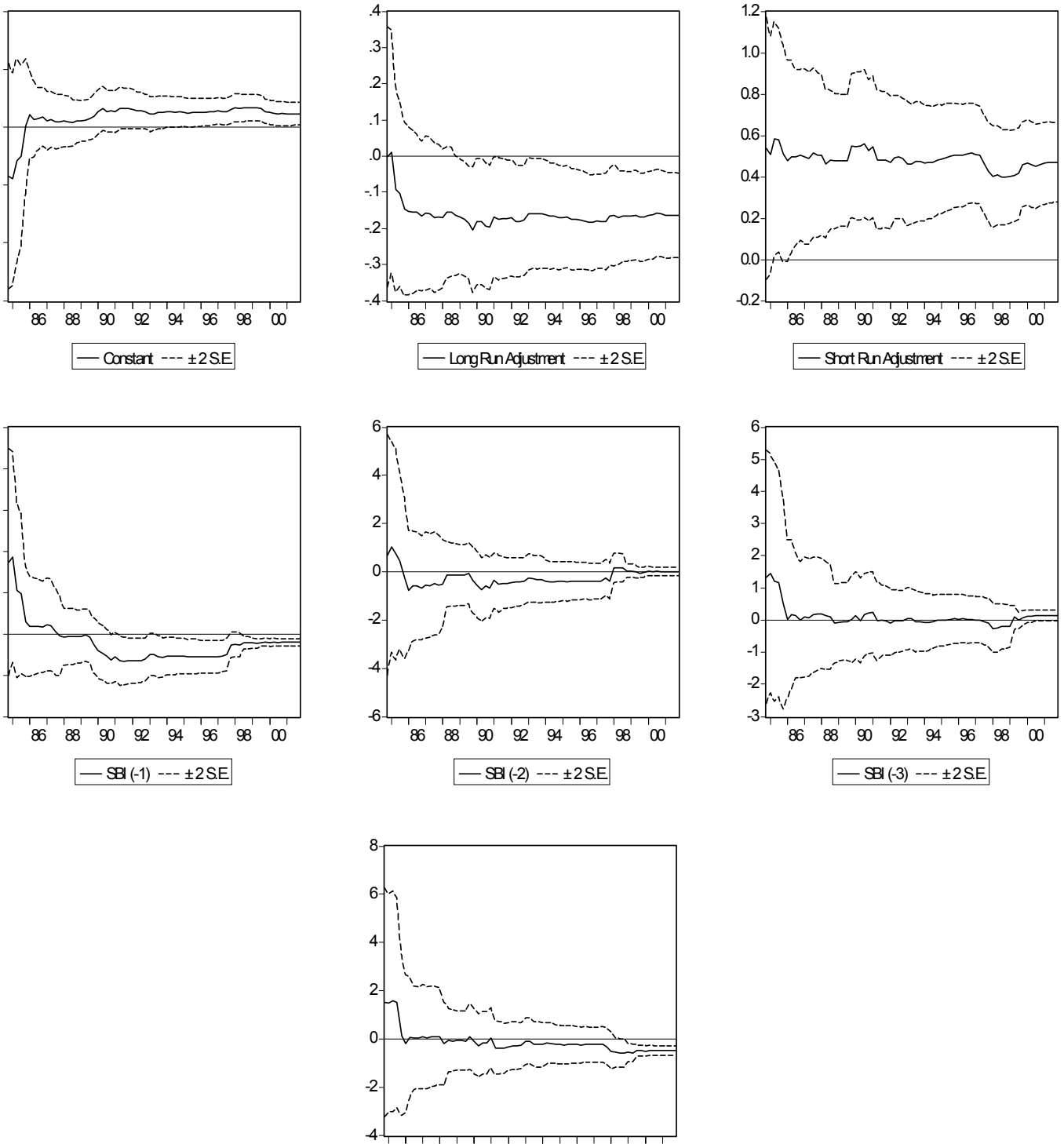


\section{BIBLIOGRAPHY}

Aghevli, B, and Mohsin Khan (1977),"Inflationary Finance and The Dynamics of Inflation: Indonesia 1959 - 1972," American Economic Review, June.

Alamsyah, H. et.al (2001),"Framework for Implementing Inflation Targeting in Indonesia," Bulletin of Indonesian Economic Study,, 37 (3).

Altimari, S.N. (2001), "Does Money Lead Inflation in the Euro Area, ECB Working Paper, no. 63

Bank Indonesia, Annual Reports, Various Issues 1980-2001

Bank Indonesia, Central Bank Act 23 /1999

Bernanke, B., Laubach, T., Mishkin, F., Posen, A. (1999), Inflation Targeting, Princeton University Press

Beyer, A (1998), " Modelling Money Demand in Germany," Journal of Applied Econometrics, 13, p $57-76$

Boswijk, H.P (1992)," Cointegration, Identification, and Exogeneity: Inference in Structural Error Correction Models," Tinbergen Institute Research Series

Brand C and Cassola, N (2000),"A Money Demand System for Euro Area M3," ECB Working Paper no 39

Bry, G and Charlotte Boschan (1971),"Cyclical Analysis of Time Series: Selected Procedures and Computer Programs," NBER

Bryant, R.C. (1980), Money and Monetary Policy in Interdependent Nations, Brookings Institution, Washington

Chari, V (1999), "Nobel Laurate Robert E. Lucas, Jr.: Architect of Modern Macroeconomics", Federal Reserves Bank of Minneapolis

Coenen G, and J.L. Vega (1999)," The Demand for M3 in the Euro Area, ECB Working Paper No. 612.

Dekle, P and Mahmood Pradhan (1999), Financial Liberalization and Money Demand in the ASEAN Countries," International Journal of Finance and Economics, 4 (3), p 205-215 